\title{
Switching Catalyst Selectivity via the Introduction of a Pendant Nitrophenyl Group
}

\author{
Eric M. Johnson, Jeffrey J. Liu, Adam D. Samuel, Ralf Haiges, Smaranda C. Marinescu*
}

Department of Chemistry, University of Southern California, Los Angeles, California 90089, United States

*email: smarines@usc.edu 


\section{EXPERIMENTAL METHODS}

General. Manipulations of air and moisture sensitive materials were carried out under nitrogen either in a Vacuum Atmospheres drybox or on a dual-manifold Schlenk line. All solvents were degassed with nitrogen and passed through activated alumina columns and stored over $4 \AA$ Lindetype molecular sieves. The $\mathbf{L}^{\mathrm{NO2}}$ ligand was prepared according to literature precedent. ${ }^{1,2}$ All other chemical reagents were purchased from chemical vendors and used without further purification.

Physical Methods. NMR spectra were obtained using a Varian Mercury $400 \mathrm{MHz}$ NMR Spectrometer.

Elemental analyses were performed by Complete Analysis Laboratories, Inc., Parsippany, New Jersey, 07054 or Robertson Microlit Laboratories, 1705 U.S. Highway 46, Suite 1D, Ledgewood, New Jersey, 07852.

UV-Vis spectra were obtained using a Lambda 950 UV/Vis/NIR Spectrophotometer.

FT-IR spectra were acquired using a Bruker Vertex $80 \mathrm{v}$ spectrometer. Samples $(2 \mathrm{mg})$ for analysis were mixed into a $\mathrm{KBr}(100 \mathrm{mg})$ matrix and pressed into pellets.

The single-crystal X-ray diffraction data were collected on a Bruker SMART APEX DUO 3circle platform diffractometer, equipped with an APEX II CCD, using Mo Ka radiation (TRIUMPH curved-crystal monochromator) from a fine-focus tube. The diffractometer was equipped with an Oxford Cryosystems Cryostream 700 apparatus for low-temperature data collection. The frames were integrated using the SAINT algorithm to give the hkl files corrected for Lp/decay. ${ }^{3}$ The absorption correction was performed using the SADABS program. ${ }^{4}$ The structures were solved by intrinsic phasing and refined on $\mathrm{F}^{2}$ using the Bruker SHELXTL Software Package and ShelXle. ${ }^{5}$ All non-hydrogen atoms were refined anisotropically.

Electrochemical Methods. Electrochemical experiments were carried out using a Pine potentiostat. The electrochemical experiments were carried out in a three-electrode configuration electrochemical cell as described below under nitrogen or carbon dioxide atmospheres. All experiments were resistance corrected.

Cyclic Voltammetry of $\mathbf{L}^{\mathrm{NO} 2}$ and $\mathbf{C o L}^{\mathrm{NO} 2}$. Electrochemical studies of $\mathbf{L}^{\mathrm{NO} 2}(0.5 \mathrm{mM})$ and $\mathbf{C o L}^{\mathrm{NO2}}(0.5 \mathrm{mM})$ were performed in anhydrous dimethylformamide with tetrabutylammonium hexafluorophosphate $\left(\mathrm{TBAPF}_{6}\right)(0.1 \mathrm{M})$ as the supporting electrolyte. Platinum wire was used as the counter electrode, silver wire as the reference electrode, and glassy carbon as the working electrode. Decamethylferrocene was added as an internal standard to reference to ferrocene $\left(\mathrm{Fc}^{+/ 0}\right)$, and all potentials are given with reference to ferrocene. Samples were sparged with $\mathrm{N}_{2}$ or $\mathrm{CO}_{2}$ gas for 10 minutes before experiments.

Controlled Potential Electrolysis. Controlled potential electrolysis (CPE) measurements to determine Faradaic efficiency were conducted in a sealed two-chambered $\mathrm{H}$ cell where the first chamber held the working and reference electrodes in $40 \mathrm{~mL}$ of electrolyte and the second chamber held the auxiliary electrode in $20 \mathrm{~mL}$ of electrolyte. CPE experiments were performed 
in $0.1 \mathrm{M} \mathrm{TBAPF}_{6}$ DMF solutions with $0.5 \mathrm{mM}$ of analyte. Glassy carbon plate electrodes $(6 \mathrm{~cm}$ $\times 1 \mathrm{~cm} \times 0.3 \mathrm{~cm}$; Tokai Carbon USA) were used as the working and auxiliary electrodes. The reference electrode was a $\mathrm{Ag}$ wire separated from the solution by a Vycor tip. The working compartment was sparged with $\mathrm{N}_{2}$ or $\mathrm{CO}_{2}$ for 10 minutes before the experiment. The two chambers were both under $\mathrm{N}_{2}$ or $\mathrm{CO}_{2}$ and separated by a fine porosity glass frit. Using a gas-tight syringe, $2 \mathrm{~mL}$ of gas were withdrawn from the headspace of the $\mathrm{H}$ cell and injected into a gas chromatography instrument (Shimadzu GC-2010-Plus) equipped with a BID detector and a Restek ShinCarbon ST Micropacked column. To determine the Faradaic efficiency, the theoretical $\mathrm{CO}$ amount based on total charge flowed is compared with the GC-detected $\mathrm{CO}$ produced from the controlled-potential electrolysis experiment.

\section{SYNTHETIC METHODS}

The macrocycle $(\mathrm{NH})_{1}(\mathrm{NMe})_{3}$-bridged calix[4]pyridine was prepared according to literature precedent. ${ }^{1}$

Synthesis of $\mathbf{L}^{\mathrm{NO2}}$. The ligand was synthesized using the following literature procedure. ${ }^{2} \mathrm{~A}$ dry flask under nitrogen was charged with $(\mathrm{NH})_{1}(\mathrm{NMe})_{3}$-bridged calix[4]pyridine $(69.7 \mathrm{mg}, 0.17$ $\mathrm{mmol})$, cesium carbonate $(162.3 \mathrm{~g}, 0.50 \mathrm{mmol})$, and 2-fluoronitrobenzene $(0.13 \mathrm{~mL}, 1.23 \mathrm{mmol})$. DMF $(14 \mathrm{~mL})$ was added, and the solution was heated to $60{ }^{\circ} \mathrm{C}$ for 24 hours. The solution was extracted into ethyl acetate and washed with water. The organic phase was dried with $\mathrm{Na}_{2} \mathrm{SO}_{4}$ and concentrated. The residue was purified via column chromatography with 2:1 hexanes/ethyl acetate to obtain the product as a brown powder in $95 \%$ yield.

Synthesis of $\mathbf{C o L}^{\mathrm{NO} 2}$. A 1:1 ratio of $\mathbf{L}^{\mathrm{NO2}}$ and $\mathrm{Co}\left(\mathrm{ClO}_{4}\right)_{2} \cdot 6 \mathrm{H}_{2} \mathrm{O}$ were dissolved in chloroform and acetonitrile, respectively. The two solutions were then mixed and stirred for 30 minutes at room temperature. The solvent was subsequently removed by rotary evaporation to give $\mathbf{C o L}^{\mathrm{NO2}}$ as a brown powder in quantitative yields. X-ray quality crystals were grown by suspending the powder in chloroform, adding acetonitrile dropwise until dissolution, and vapor diffusing diethyl ether into the reaction mixture. ${ }^{1} \mathrm{H} \mathrm{NMR}\left(400 \mathrm{MHz}, \mathrm{CD}_{3} \mathrm{CN}\right) \delta 9.91,9.65,9.29,7.36,7.05,5.13$, 3.20, 1.13. ${ }^{1} \mathrm{H}$ NMR (400 MHz, Py- $d_{5}$ ) $\delta 31.50,28.82,25.36,22.37,13.98,12.90,12.20,10.05$. Anal. Calcd. for $\mathrm{C}_{33} \mathrm{H}_{31} \mathrm{~N}_{11} \mathrm{O}_{10} \mathrm{Cl}_{2} \mathrm{Co}$ : C, 42.83; H, 3.41; N, 15.00. Found: C, 44.84; H, 3.40; N, 16.87. 


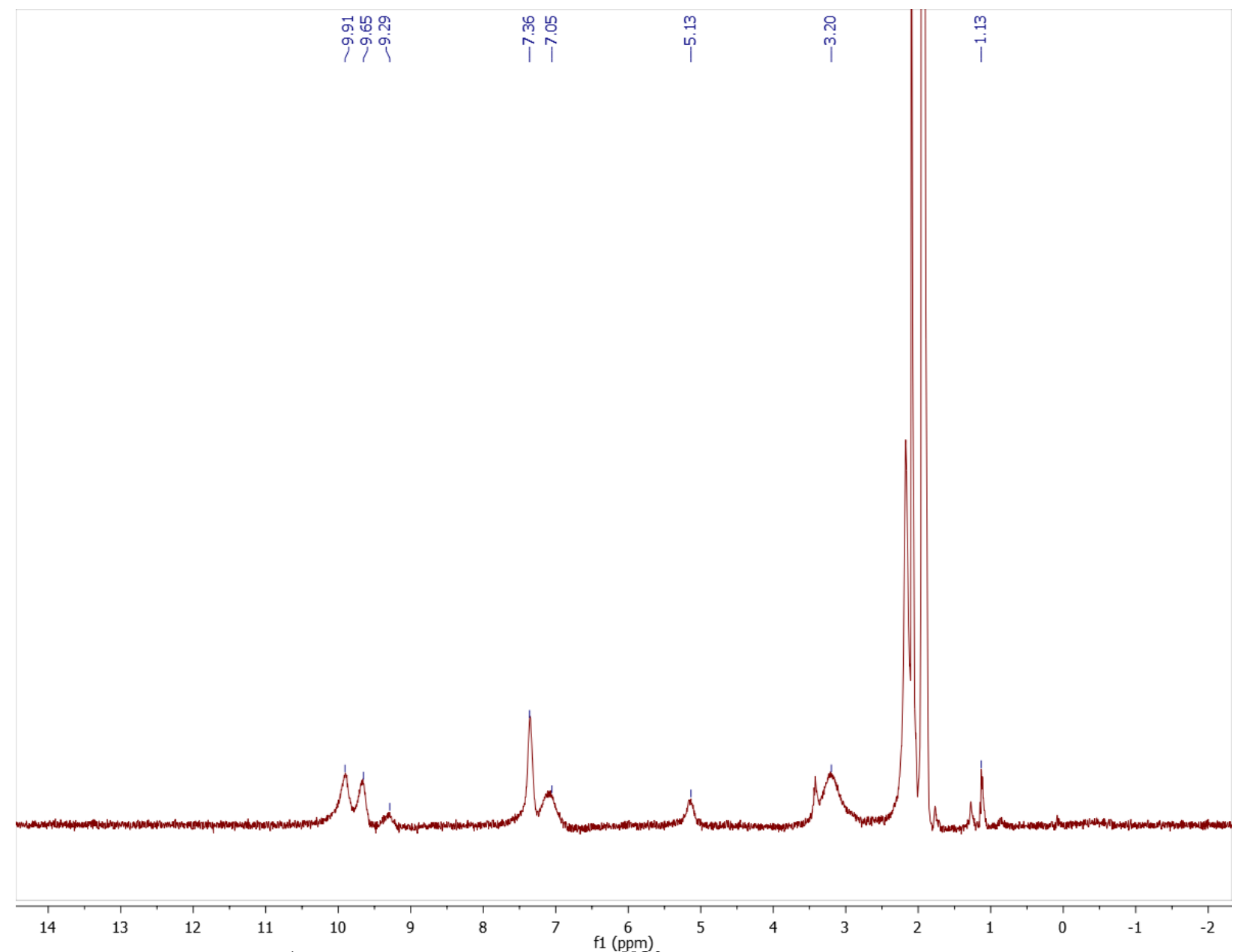

Figure S1. $400 \mathrm{MHz}{ }^{1} \mathrm{H}$ NMR spectrum of $\mathbf{C o L} \mathbf{L}^{\mathrm{NO2}}$ in $\mathrm{CD}_{3} \mathrm{CN}$. 

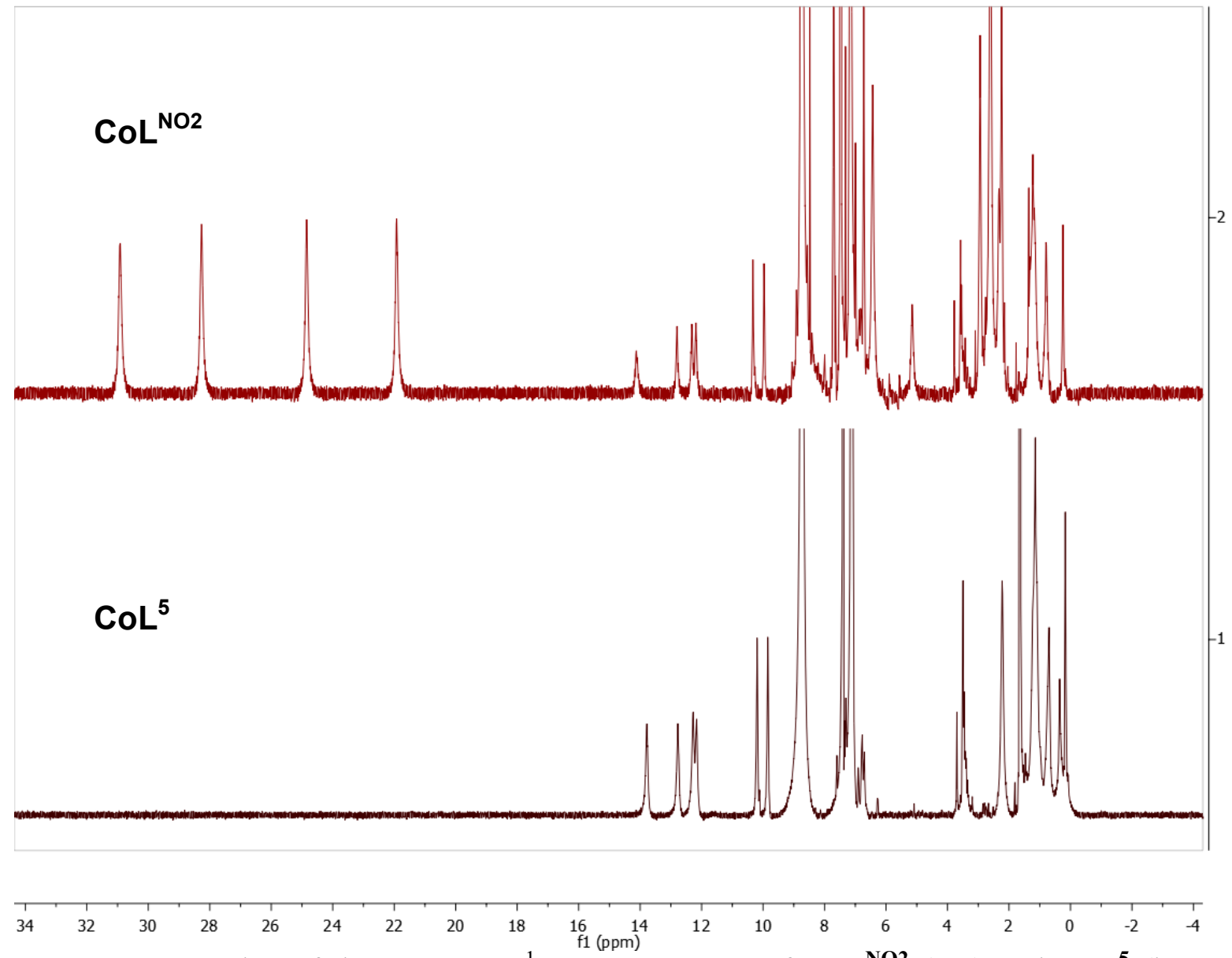

Figure S2. Overlay of the $400 \mathrm{MHz}{ }^{1} \mathrm{H}$ NMR spectra of $\mathbf{C o L}^{\mathbf{N O 2}}$ (top) and $\mathbf{C o L}^{\mathbf{5}}$ (bottom) in pyridine- $d_{5}$.

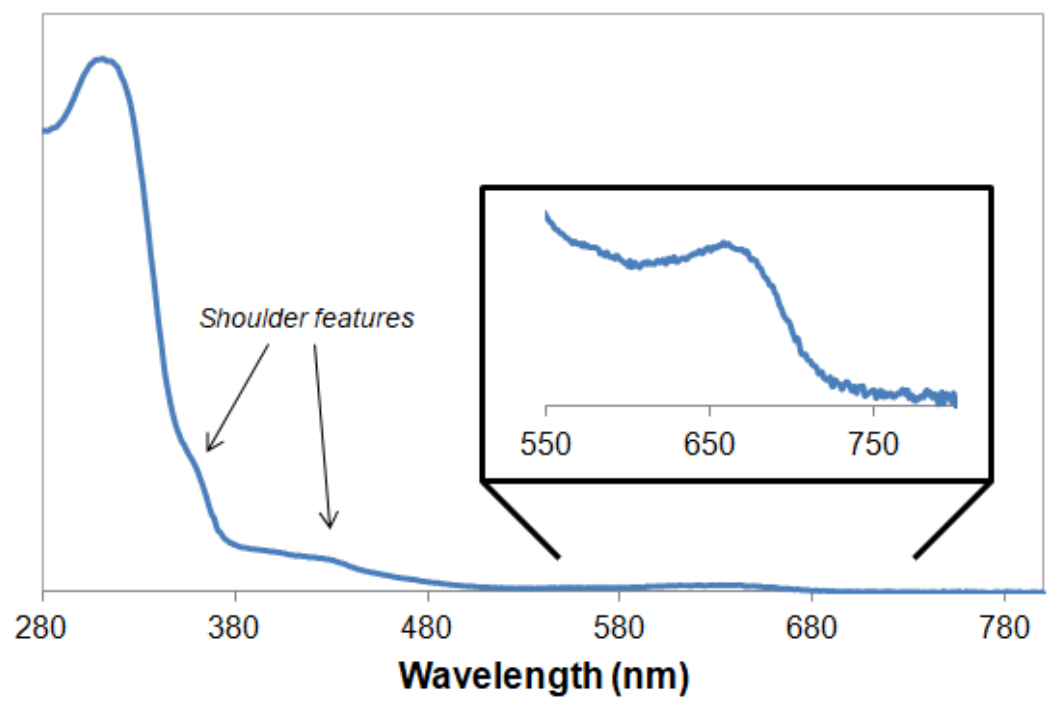

Figure S3. UV-Vis spectrum of CoL ${ }^{\text {NO2 }}$ in a DMF solution. $\lambda_{\max }: 311 \mathrm{~nm}, 359$ (sh.) nm, 427 (sh.) nm, $660 \mathrm{~nm}$. 


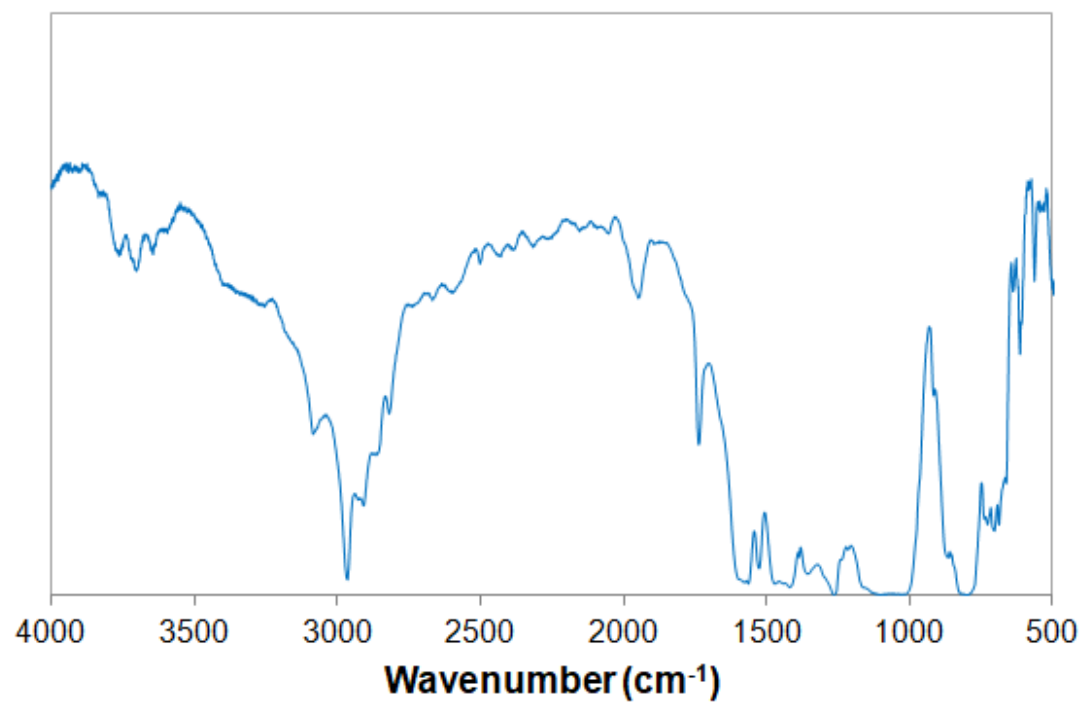

Figure S4. FTIR spectrum of $\mathbf{L}^{\mathrm{NO2}}$.

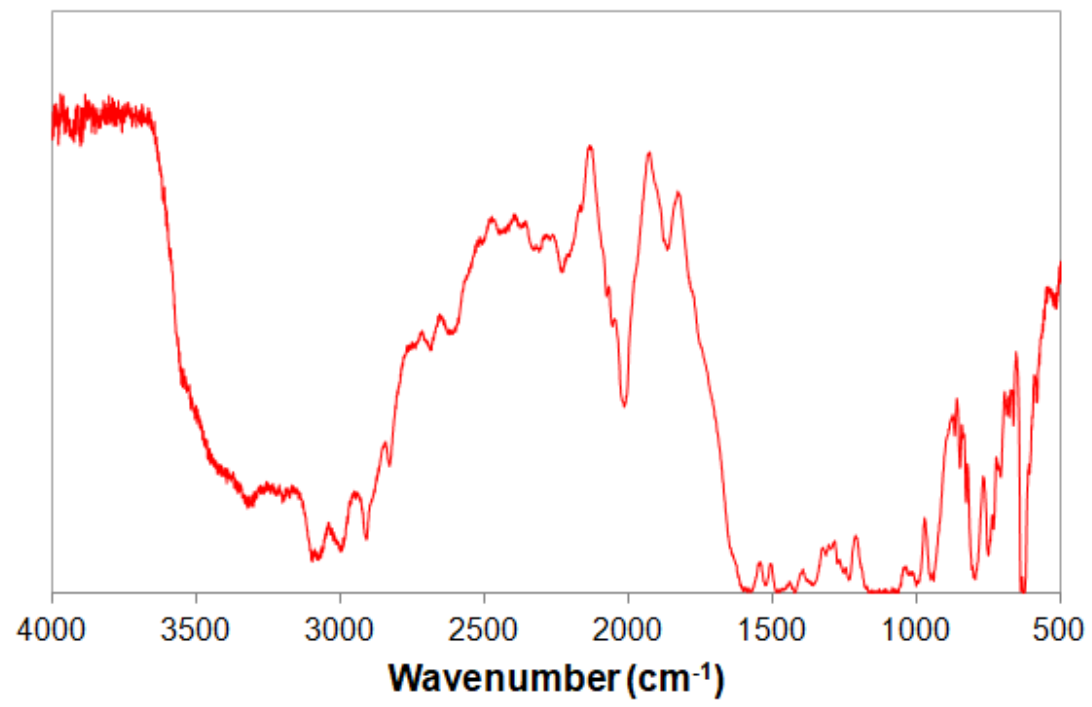

Figure S5. FTIR spectrum of $\mathrm{CoL}^{\mathrm{NO2}}$. 


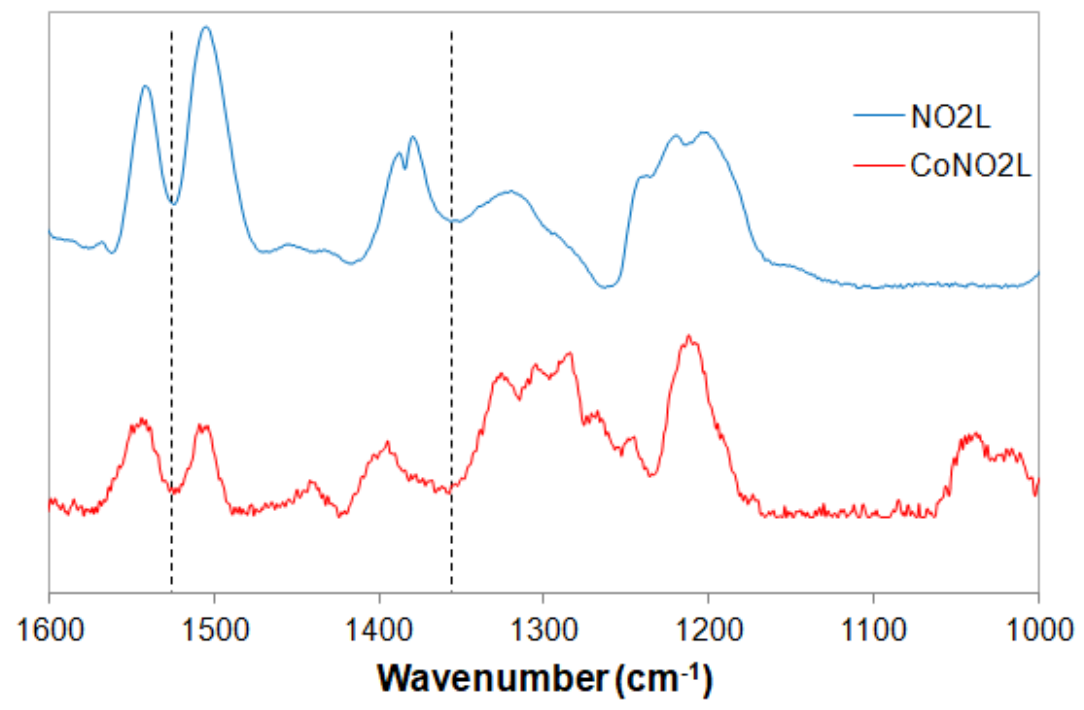

Figure S6. FTIR spectrum overlay of the $\mathrm{NO}_{2}$ regions of $\mathbf{L}^{\mathrm{NO2}}$ and $\mathbf{C o L}^{\mathrm{NO} 2}$. Highlighted (dotted line) are the features at 1524 and $1360 \mathrm{~cm}^{-1}$, which are ascribed to the vibrational modes of the ligand nitro group.

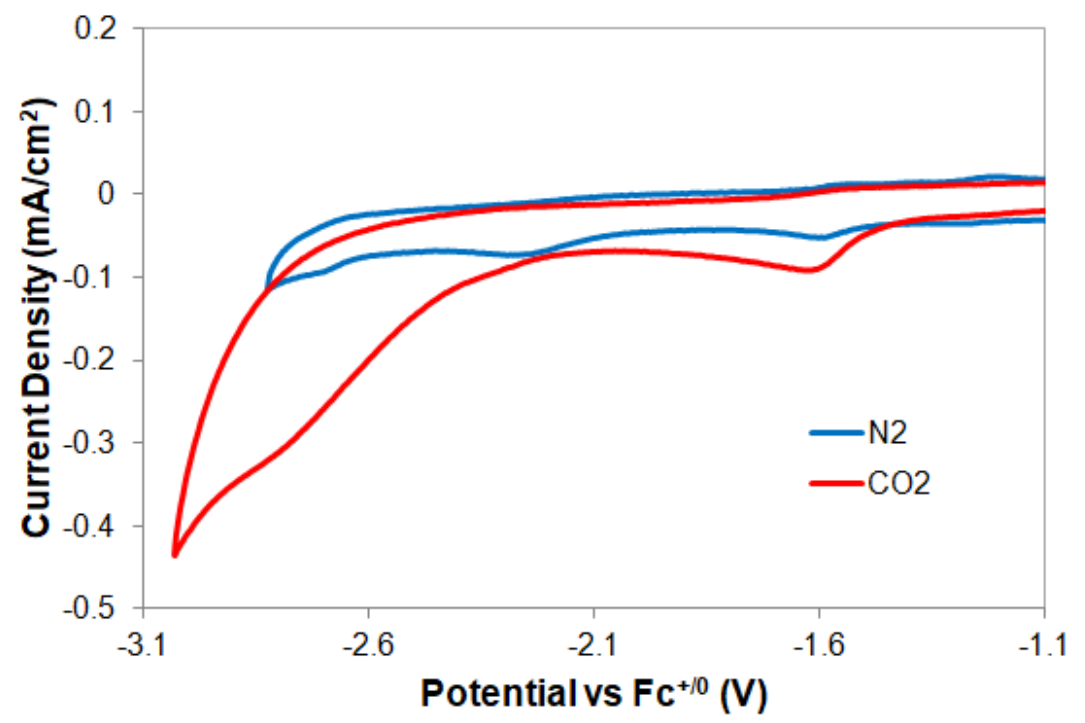

Figure S7. Cyclic voltammograms of $0.5 \mathrm{mM} \mathrm{L}^{\mathrm{NO2}}$ in $0.1 \mathrm{M} \mathrm{TBAPF}_{6} \mathrm{MeCN}$ under $\mathrm{N}_{2}$ (blue) and $\mathrm{CO}_{2}$ (red) atmospheres. Scan rate $=100 \mathrm{mV} / \mathrm{s}$. 


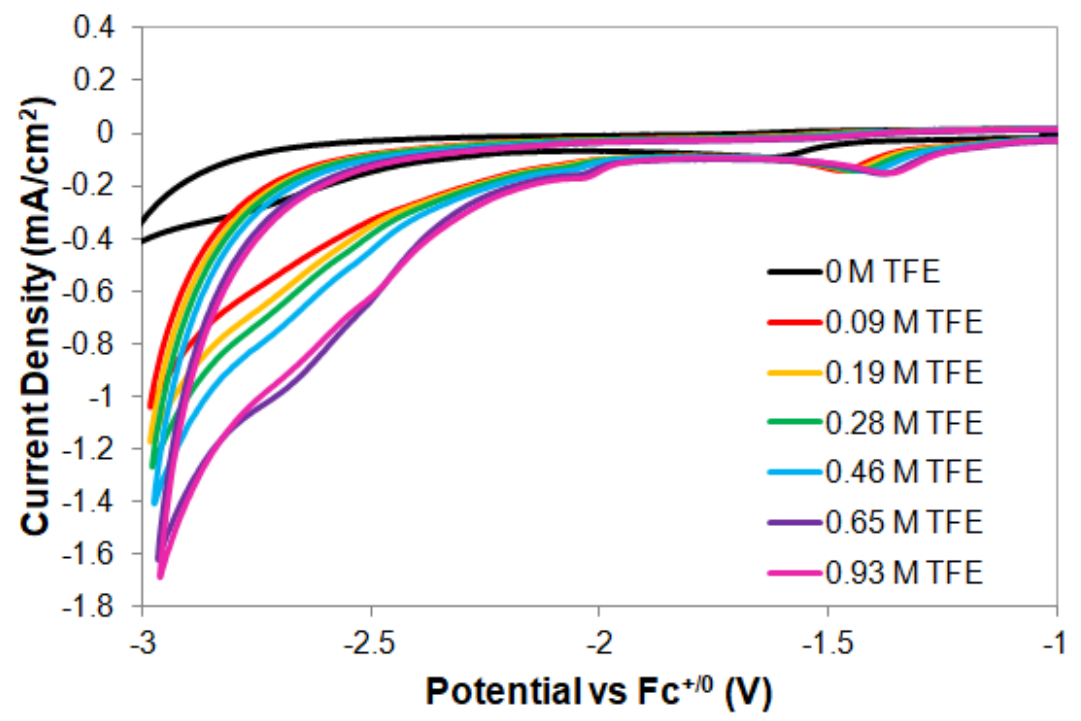

Figure S8. Cyclic voltammograms of $0.5 \mathrm{mM} \mathrm{L} \mathbf{L}^{\mathrm{NO} 2}$ in $0.1 \mathrm{M} \mathrm{TBAPF}_{6} \mathrm{MeCN}$ under a $\mathrm{CO}_{2}$ atmosphere upon addition of varying amounts of 2,2,2-trifluoroethanol (TFE). Scan rate $=100$ $\mathrm{mV} / \mathrm{s}$.
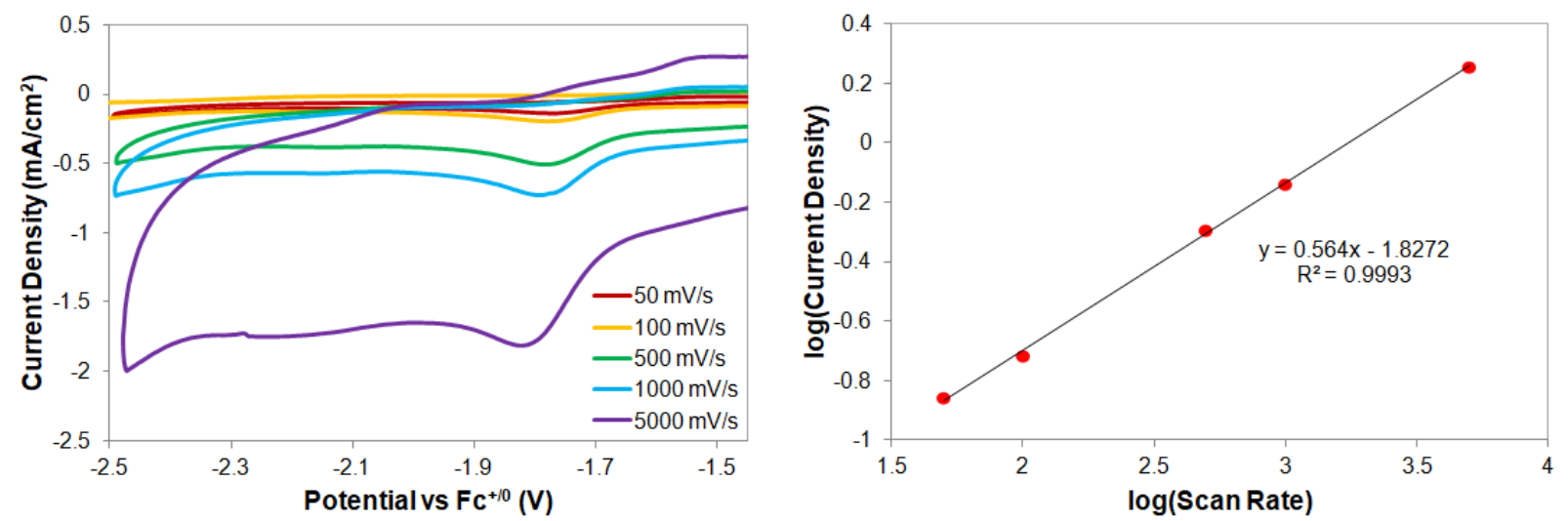

Figure S9. (A) Cyclic voltammograms of $\mathbf{C o L}^{\mathrm{NO2}}(0.5 \mathrm{mM})$ in $\mathrm{MeCN}$ with $0.1 \mathrm{M} \mathrm{TBAPF}_{6}$ under $\mathrm{N}_{2}$ with varied scan rates with (B) a corresponding plot of $\log$ (current density) vs $\log$ (scan rate). 


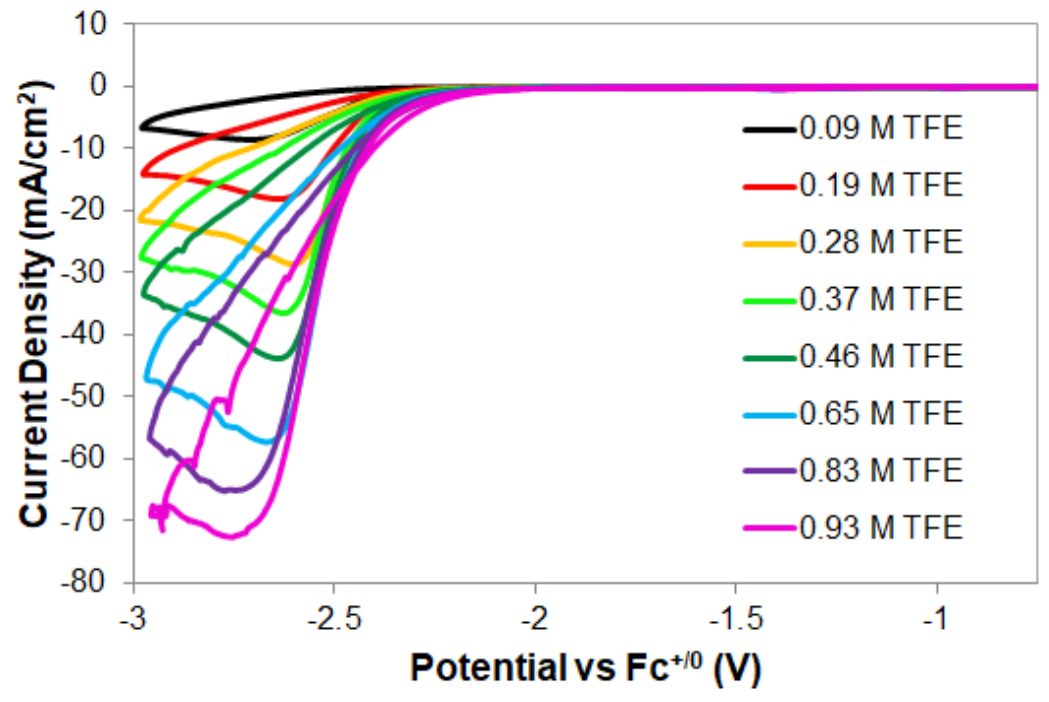

Figure S10. Cyclic voltammograms of $0.5 \mathrm{mM} \mathrm{CoL}^{\mathrm{NO2}}$ in $0.1 \mathrm{M} \mathrm{TBAPF}_{6} \mathrm{MeCN}$ solution under an $\mathrm{N}_{2}$ atmosphere with increasing amounts of TFE. Scan rate $=100 \mathrm{mV} / \mathrm{s}$.

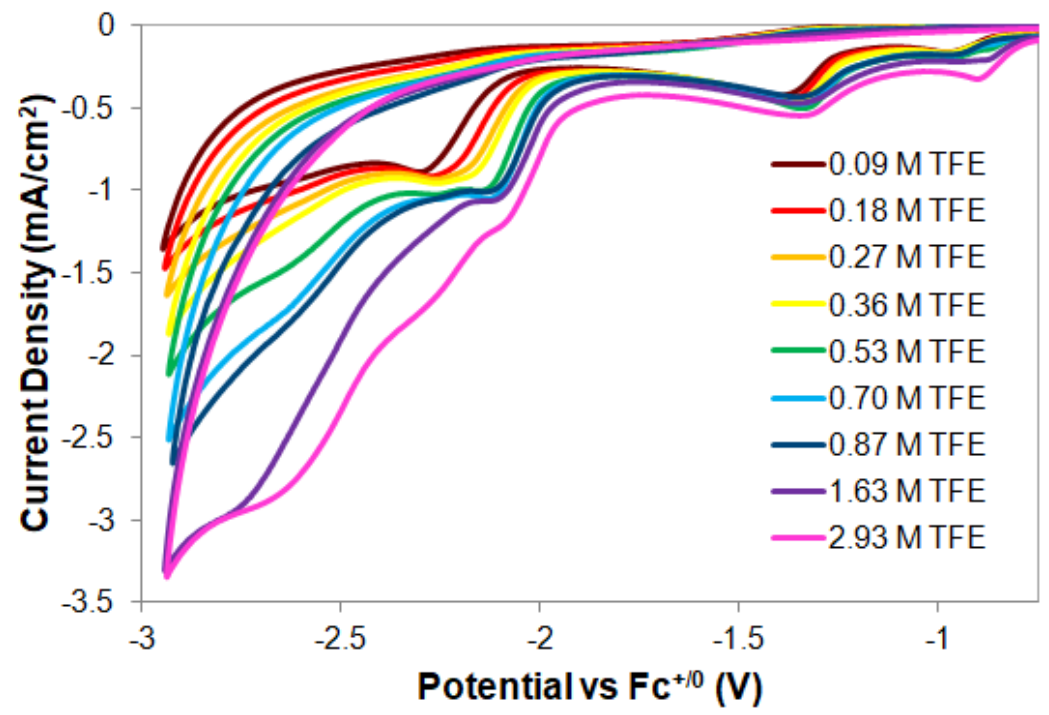

Figure S11. Cyclic voltammograms of $0.5 \mathrm{mM} \mathrm{CoL}^{\mathrm{NO2}}$ in $0.1 \mathrm{M} \mathrm{TBAPF}_{6} \mathrm{MeCN}$ solution under a $\mathrm{CO}_{2}$ atmosphere with increasing amounts of TFE. Scan rate $=100 \mathrm{mV} / \mathrm{s}$. 


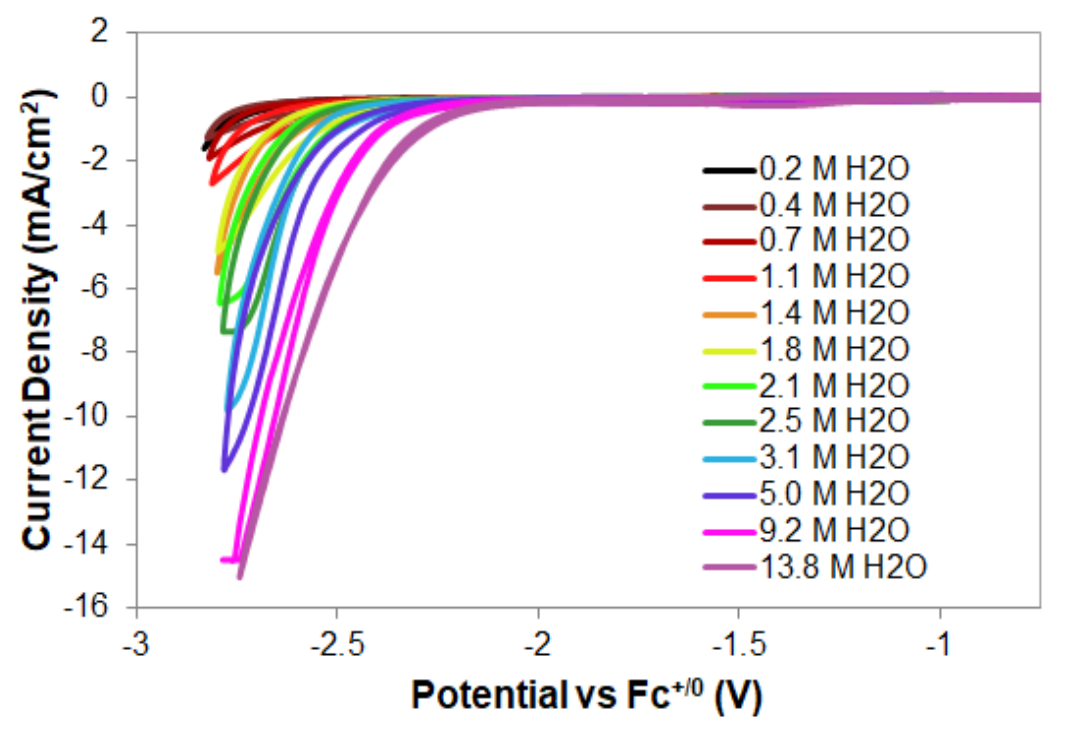

Figure S12. Cyclic voltammograms of $0.5 \mathrm{mM} \mathrm{CoL}^{\mathrm{NO2}}$ in $0.1 \mathrm{M} \mathrm{TBAPF}_{6} \mathrm{MeCN}$ solution under an $\mathrm{N}_{2}$ atmosphere with increasing amounts of $\mathrm{H}_{2} \mathrm{O}$. Scan rate $=100 \mathrm{mV} / \mathrm{s}$.

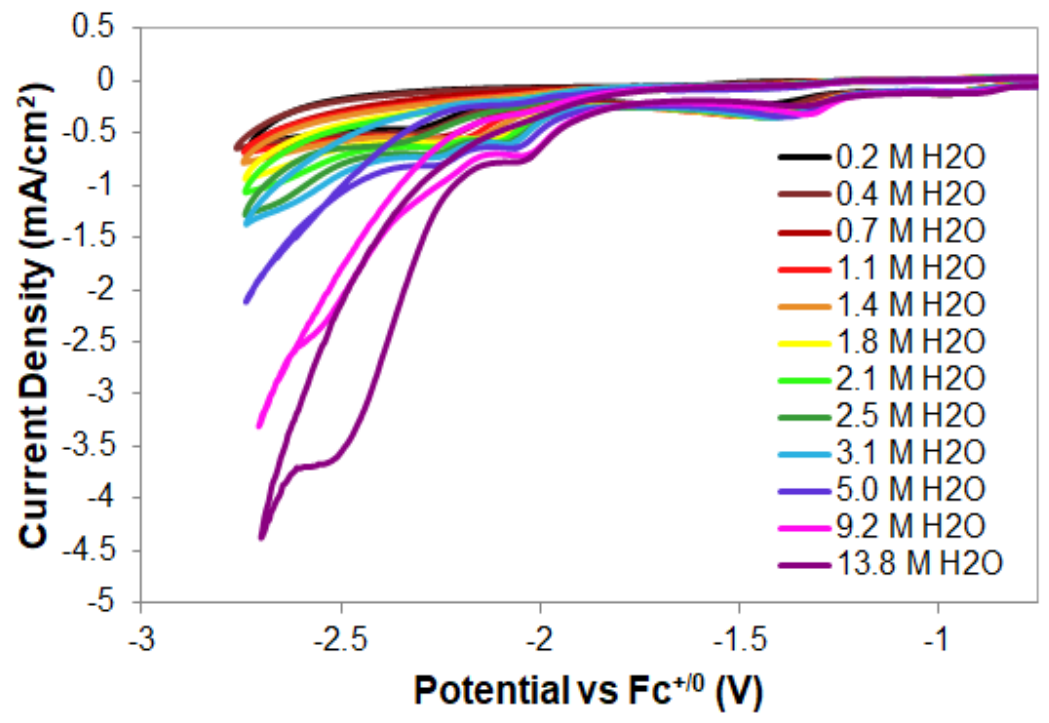

Figure S13. Cyclic voltammograms of $0.5 \mathrm{mM} \mathrm{CoL} \mathbf{C}^{\mathrm{NO} 2}$ in $0.1 \mathrm{M}$ TBAPF $6 \mathrm{MeCN}$ solution under a $\mathrm{CO}_{2}$ atmosphere with increasing amounts of $\mathrm{H}_{2} \mathrm{O}$. Scan rate $=100 \mathrm{mV} / \mathrm{s}$. 


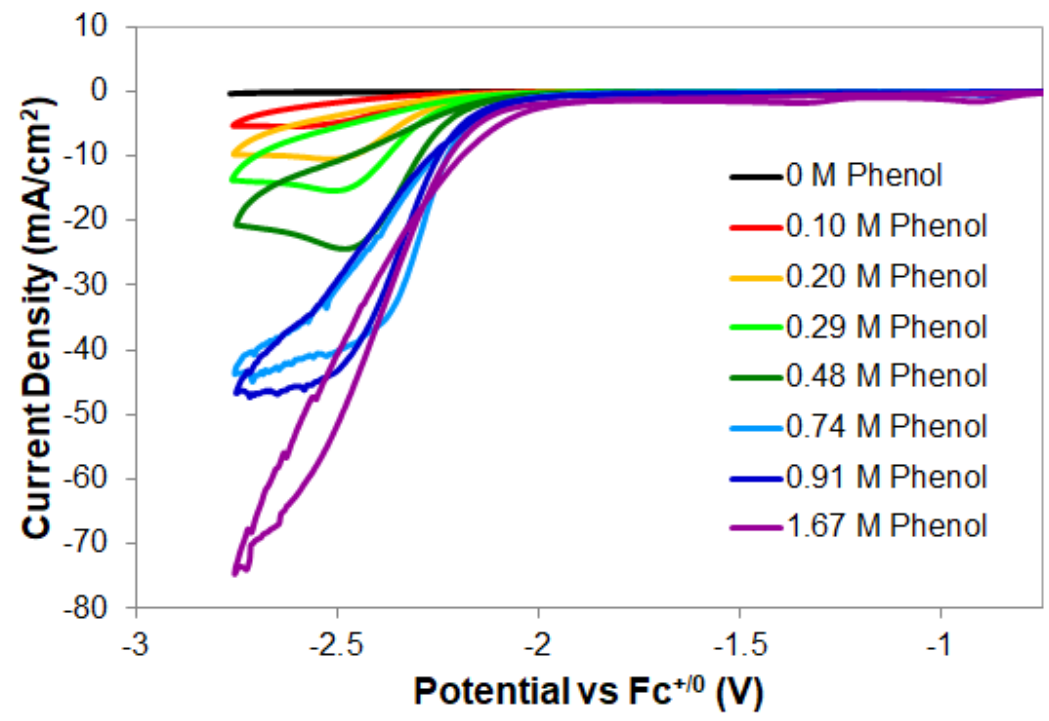

Figure S14. Cyclic voltammograms of $0.5 \mathrm{mM} \mathrm{CoL}^{\mathrm{NO2}}$ in $0.1 \mathrm{M} \mathrm{TBAPF}_{6} \mathrm{MeCN}$ solution under an $\mathrm{N}_{2}$ atmosphere with increasing amounts of $\mathrm{PhOH}$. Scan rate $=100 \mathrm{mV} / \mathrm{s}$.

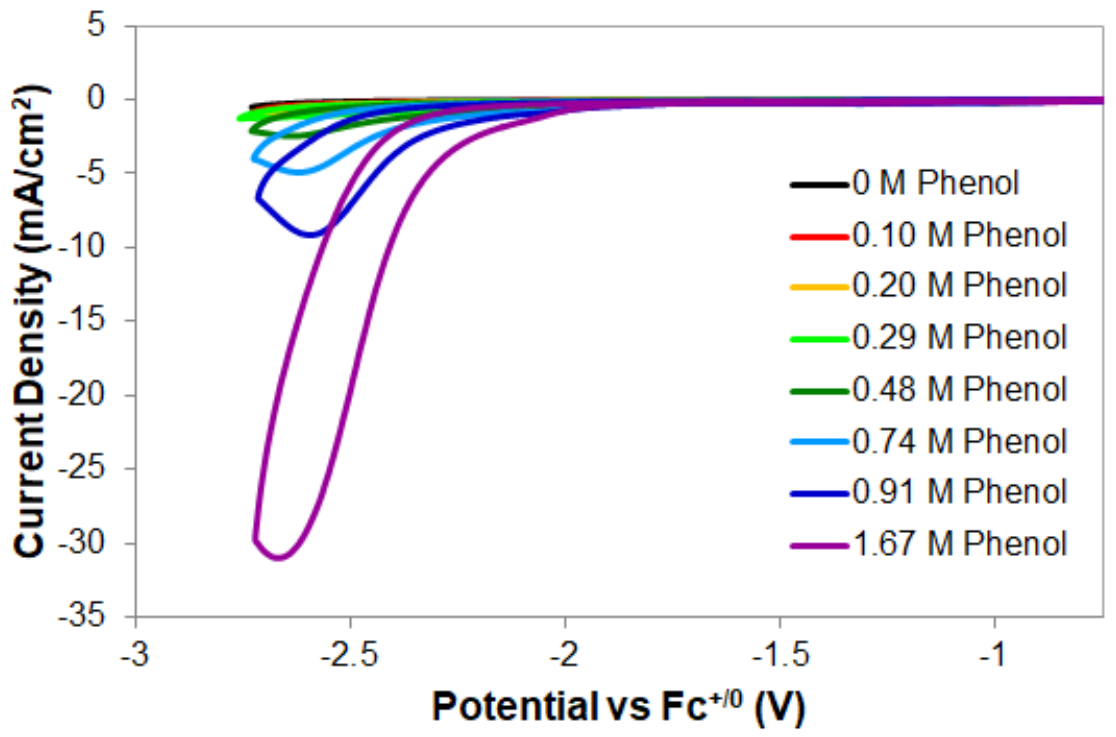

Figure S15. Cyclic voltammograms of $0.5 \mathrm{mM} \mathrm{CoL} \mathbf{L}^{\mathrm{NO} 2}$ in $0.1 \mathrm{M} \mathrm{TBAPF}_{6} \mathrm{MeCN}_{\text {solution under }}$ $\mathrm{a} \mathrm{CO}_{2}$ atmosphere with increasing amounts of $\mathrm{PhOH}$. Scan rate $=100 \mathrm{mV} / \mathrm{s}$. 


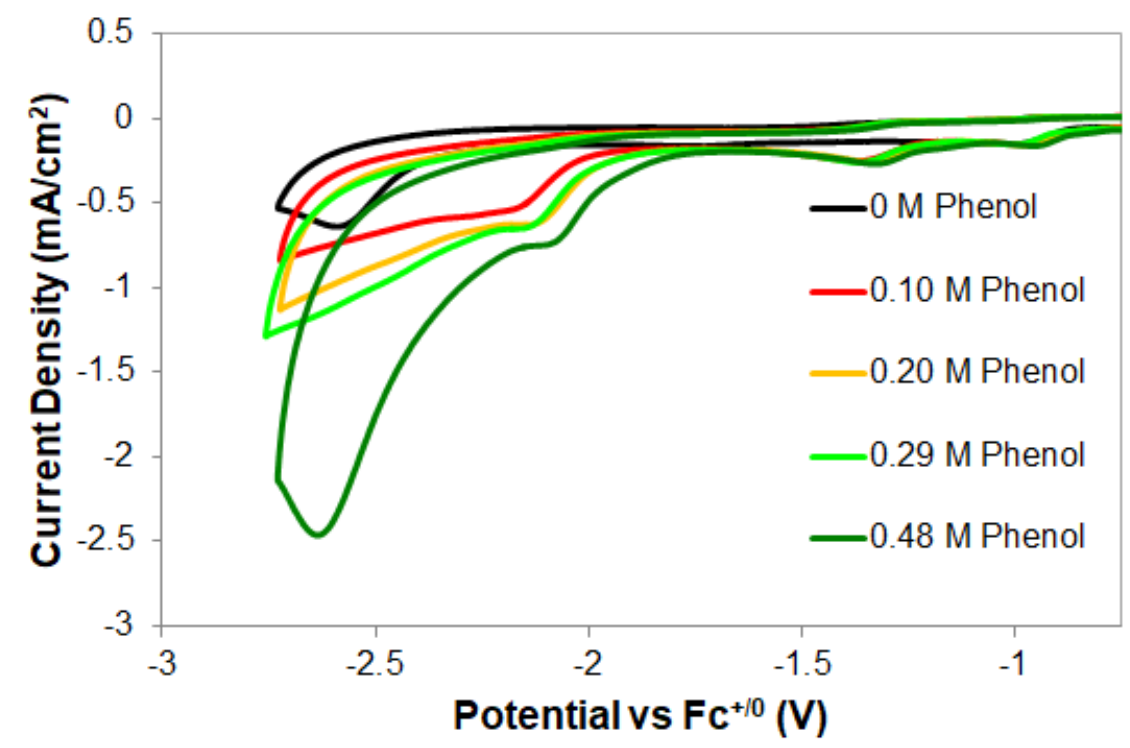

Figure S16. Cyclic voltammograms of $0.5 \mathrm{mM} \mathrm{CoL}^{\mathrm{NO2}}$ in $0.1 \mathrm{M} \mathrm{TBAPF}_{6} \mathrm{MeCN}_{\text {solution under }}$ a $\mathrm{CO}_{2}$ atmosphere with increasing amounts of $\mathrm{PhOH}$. Low concentrations of PhOH only. Scan rate $=100 \mathrm{mV} / \mathrm{s}$.

\begin{tabular}{|c|c|c|c|c|}
\hline \multirow{2}{*}{} & \multicolumn{2}{|c|}{$\mathbf{H}_{2}$} & \multicolumn{2}{c|}{ CO } \\
\cline { 2 - 5 } & $\boldsymbol{\mu m o l}$ & $\mathbf{F E ~ ( \% )}$ & $\boldsymbol{\mu m o l}$ & FE (\%) \\
\hline $\mathbf{2} \mathbf{~ h r}$ & 599.8 & 76 & 0 & 0 \\
\hline $\mathbf{4} \mathbf{~ h r}$ & 718.6 & 68 & 0 & 0 \\
\hline $\mathbf{6} \mathbf{~ h r}$ & 796.7 & 64 & 0 & 0 \\
\hline $\mathbf{8} \mathbf{~ h r}$ & 860.5 & 61 & 0 & 0 \\
\hline $\mathbf{2 4} \mathbf{~ h r}$ & 1,127 & 45 & 0 & 0 \\
\hline
\end{tabular}

Table S1. Results of 24 hour controlled potential electrolysis of $0.5 \mathrm{mM} \mathrm{CoL}{ }^{\mathrm{NO2}}$ in acetonitrile under $\mathrm{N}_{2}$ with $0.87 \mathrm{M} \mathrm{TFE}$ and $0.1 \mathrm{M} \mathrm{TBAPF}_{6}$ at $-2.70 \mathrm{~V} \mathrm{vs} \mathrm{Fc}^{+/ 0}$.

\begin{tabular}{|c|c|c|c|c|c|c|}
\hline \multirow{2}{*}{} & \multicolumn{2}{|c|}{$\mathbf{H}_{\mathbf{2}}$} & \multicolumn{2}{c|}{ CO } & \multicolumn{2}{c|}{ Formate } \\
\cline { 2 - 7 } & $\boldsymbol{\mu m o l}$ & $\mathbf{F E ~ ( \% )}$ & $\boldsymbol{\mu m o l}$ & FE (\%) & $\boldsymbol{\mu m o l}$ & FE (\%) \\
\hline $\mathbf{2} \mathbf{~ h r}$ & 6.7 & 17 & 1.8 & 4 & - & - \\
\hline $\mathbf{4} \mathbf{~ h r}$ & 30.4 & 37 & 2.8 & 3 & - & - \\
\hline $\mathbf{6} \mathbf{~ h r}$ & 65.7 & 47 & 4.5 & 3 & - & - \\
\hline $\mathbf{8} \mathbf{~ h r}$ & 108.0 & 54 & 5.5 & 3 & - & - \\
\hline $\mathbf{2 4} \mathbf{~ h r}$ & 350.3 & 58 & 13.0 & 2 & 0.4 & $<1$ \\
\hline
\end{tabular}

Table S2. Results of 24 hour controlled potential electrolysis of $0.5 \mathrm{mM} \mathrm{CoL}^{\mathrm{NO2}}$ in acetonitrile under $\mathrm{CO}_{2}$ with $0.87 \mathrm{MTFE}$ and $0.1 \mathrm{M} \mathrm{TBAPF}_{6}$ at $-2.70 \mathrm{~V} \mathrm{vs} \mathrm{Fc}^{+/ 0}$. 


\begin{tabular}{|c|c|c|c|c|c|c|}
\hline \multirow{2}{*}{} & \multicolumn{2}{|c|}{$\mathbf{H}_{2}$} & \multicolumn{2}{c|}{ CO } & \multicolumn{2}{c|}{ Formate } \\
\cline { 2 - 7 } & $\boldsymbol{\mu m o l}$ & FE (\%) & $\boldsymbol{\mu m o l}$ & FE (\%) & $\boldsymbol{\mu m o l}$ & FE (\%) \\
\hline $\mathbf{2} \mathbf{~ h r}$ & 155 & 67 & 4 & 1.5 & - & - \\
\hline $\mathbf{4} \mathbf{~ h r}$ & 265 & 69 & 5 & 1.26 & - & - \\
\hline $\mathbf{6} \mathbf{~ h r}$ & 348 & 71 & 6 & 1.18 & - & - \\
\hline $\mathbf{8} \mathbf{~ h r}$ & 406 & 69 & 6 & 1 & - & - \\
\hline $\mathbf{2 4} \mathbf{~ h r}$ & 875 & 58 & 9 & $<1$ & 0 & 0 \\
\hline
\end{tabular}

Table S3. Results of 24 hour controlled potential electrolysis of $0.5 \mathrm{mM} \mathrm{CoL}^{\mathrm{NO2}}$ in acetonitrile under $\mathrm{CO}_{2}$ with $1 \mathrm{M} \mathrm{H}_{2} \mathrm{O}$ and $0.1 \mathrm{M} \mathrm{TBAPF}_{6}$ at $-2.70 \mathrm{~V} \mathrm{vs} \mathrm{Fc}^{+/ 0}$.

\begin{tabular}{|c|c|c|c|c|c|c|}
\hline & \multicolumn{2}{|c|}{$\mathbf{H}_{\mathbf{2}}$} & \multicolumn{2}{c|}{ CO } & \multicolumn{2}{c|}{ Formate } \\
\cline { 2 - 7 } & $\boldsymbol{\mu m o l}$ & $\mathbf{F E ~ ( \% )}$ & $\boldsymbol{\mu m o l}$ & FE (\%) & $\boldsymbol{\mu m o l}$ & FE (\%) \\
\hline $\mathbf{2} \mathbf{~ h r}$ & 443 & 46 & 37 & 4 & - & - \\
\hline $\mathbf{4} \mathbf{~ h r}$ & 679 & 38 & 55 & 3 & - & - \\
\hline $\mathbf{6} \mathbf{~ h r}$ & 681 & 36 & 67 & 3 & - & - \\
\hline $\mathbf{8} \mathbf{~ h r}$ & 708 & 34 & 73 & 4 & - & - \\
\hline $\mathbf{2 4} \mathbf{~ h r}$ & 484 & 18 & 85 & 3 & 0 & 0 \\
\hline
\end{tabular}

Table S4. Results of 24 hour controlled potential electrolysis of $0.5 \mathrm{mM} \mathrm{CoL}^{\mathrm{NO2}}$ in acetonitrile under $\mathrm{CO}_{2}$ with $1 \mathrm{M} \mathrm{PhOH}$ and 0.1 $\mathrm{M} \mathrm{TBAPF}_{6}$ at $-2.70 \mathrm{~V}_{\mathrm{vs} \mathrm{Fe}}{ }^{+/ 0}$.
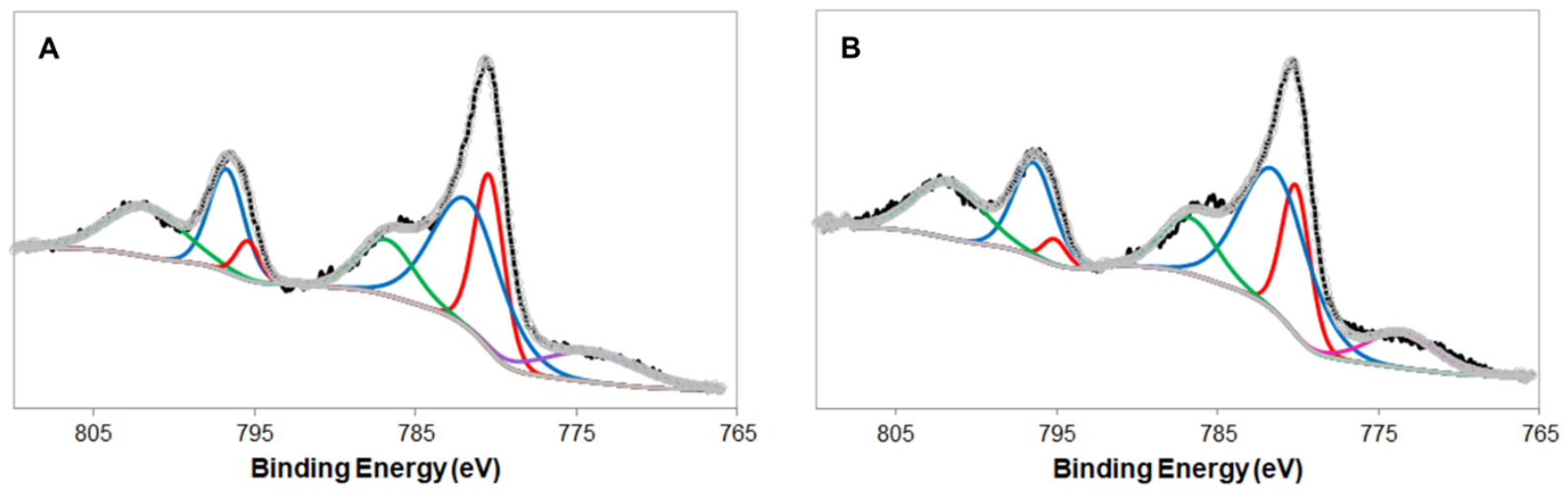

Figure S17. XPS spectra of the Co $2 p$ region for the acetonitrile (A) and acetonitrile and DMF (B) washed sections of the glassy carbon working electrode following a two hour controlled potential electrolysis of $\mathbf{C o L}^{\mathrm{NO} 2}$ with $1 \mathrm{M}$ phenol. 


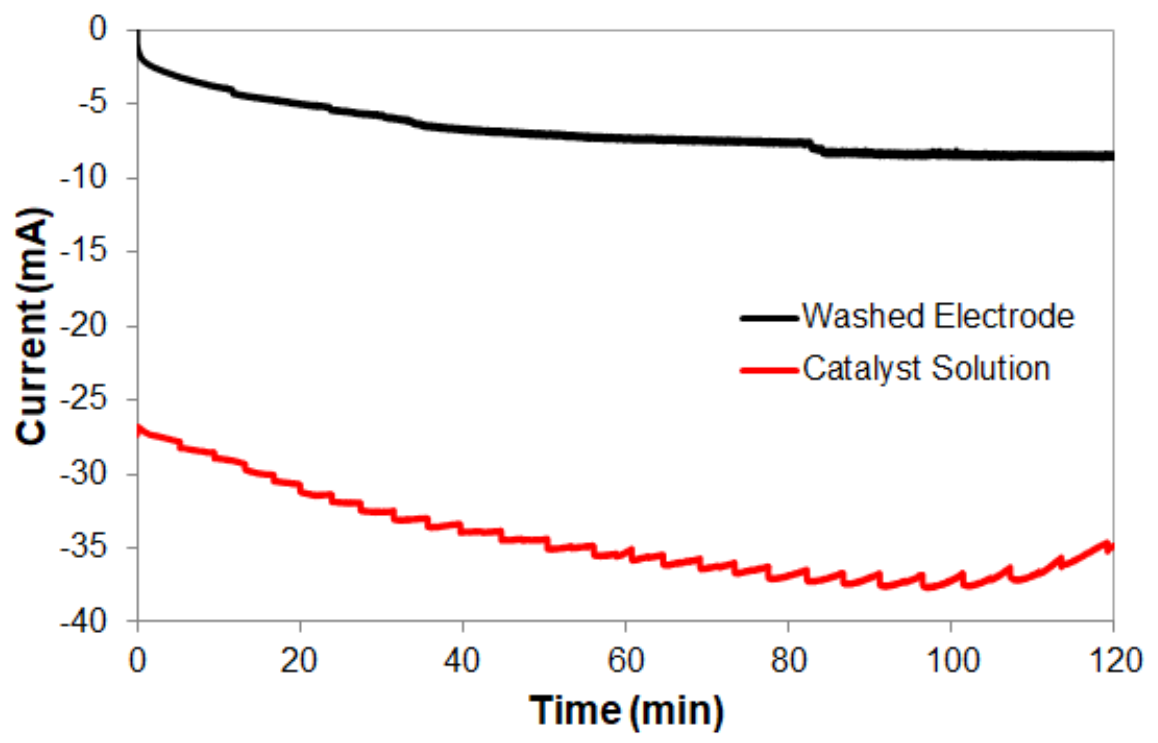

Figure S18. Controlled potential electrolysis of $1 \mathrm{M} \mathrm{PhOH}$ acetonitrile solution containing 0.5 $\mathrm{mM} \mathbf{C o L}^{\mathrm{NO2}}$ and a clean electrode (red) and a washed electrode in the absence of $\mathbf{C o L}^{\mathrm{NO2}}$ (black). $0.1 \mathrm{M} \mathrm{TBAPF}_{6}$ acetonitrile solution at $-2.70 \mathrm{~V} \mathrm{vs} \mathrm{Fc}^{+/ 0}$.

\begin{tabular}{|c|c|c|}
\hline & $\boldsymbol{\mu m o l} \mathbf{H}_{\mathbf{2}}$ & FE (\%) $\mathbf{H}_{\mathbf{2}}$ \\
\hline Washed Electrode & 139.5 & 55.1 \\
\hline Catalyst Solution & 400.2 & 31.3 \\
\hline
\end{tabular}

Table S5. Results of 2 hour controlled potential electrolysis of $0.5 \mathrm{mM} \mathrm{CoL}^{\mathrm{NO2}}$ in acetonitrile under $\mathrm{CO}_{2}$ with $1 \mathrm{M} \mathrm{PhOH}$ and $0.1 \mathrm{M} \mathrm{TBAPF}_{6}$ at $-2.70 \mathrm{~V} \mathrm{vs} \mathrm{Fc}^{+/ 0}$ (catalyst solution) and the solvent-washed electrode with no added $\mathbf{C o L}^{\mathrm{NO} 2}$ and otherwise identical conditions (washed electrode). 


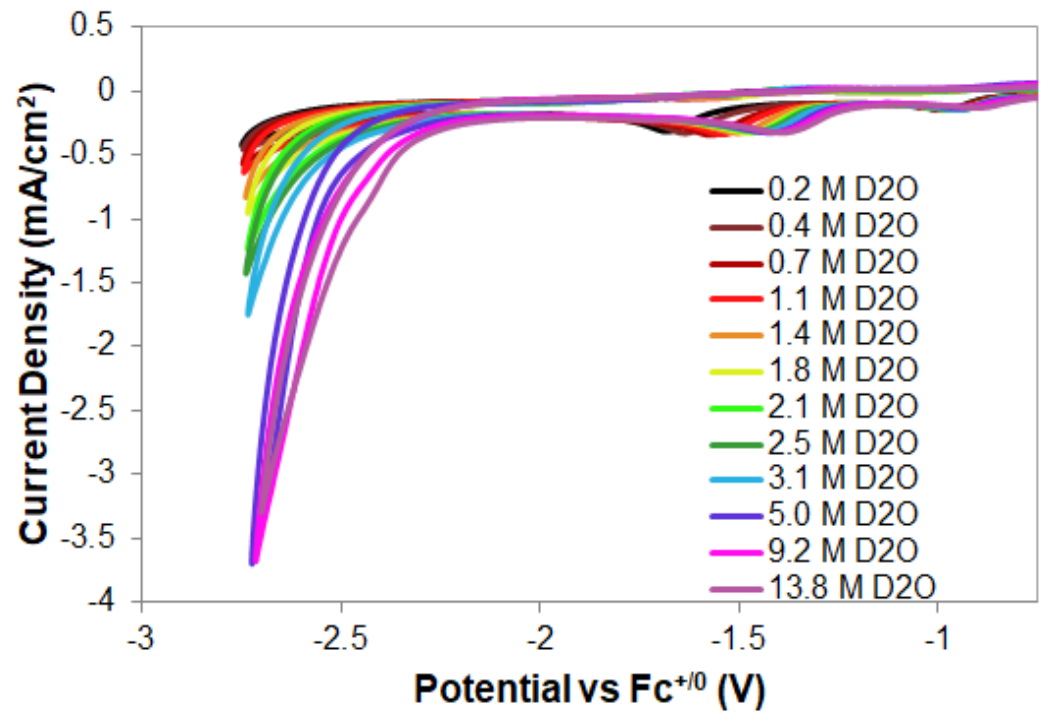

Figure S19. Cyclic voltammograms of $0.5 \mathrm{mM} \mathrm{CoL}^{\mathrm{NO2}}$ in $0.1 \mathrm{M} \mathrm{TBAPF}_{6} \mathrm{MeCN}_{\text {solution under }}$ an $\mathrm{N}_{2}$ atmosphere with increasing amounts of $\mathrm{D}_{2} \mathrm{O}$. Scan rate $=100 \mathrm{mV} / \mathrm{s}$.

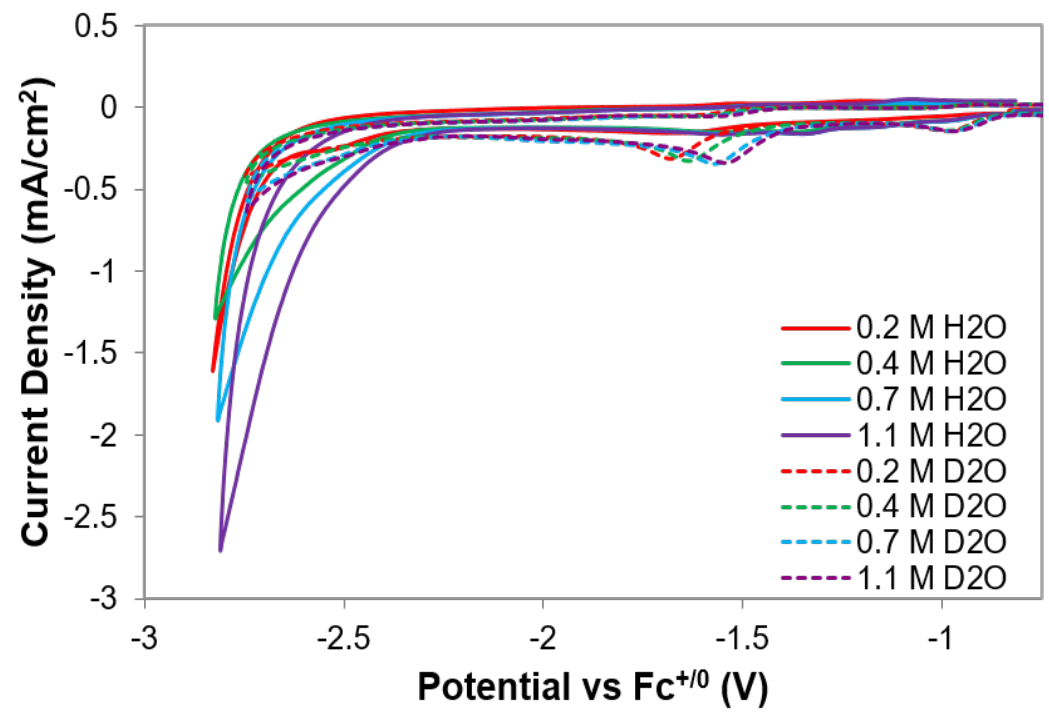

Figure S20. Cyclic voltammograms of $0.5 \mathrm{mM} \mathrm{CoL}^{\mathrm{NO2}}$ in $0.1 \mathrm{M}$ TBAPF 6 MeCN solution under an $\mathrm{N}_{2}$ atmosphere with increasing amounts of $\mathrm{H}_{2} \mathrm{O}$ (solid lines) and $\mathrm{D}_{2} \mathrm{O}$ (dashed lines). Scan rate $=100 \mathrm{mV} / \mathrm{s}$. 


\begin{tabular}{|c|c|c|c|}
\hline [Acid] $(\mathbf{M})$ & $\begin{array}{c}\boldsymbol{i}_{\max (\mathbf{H})} \\
\left(\mathbf{m A} / \mathbf{c m}^{2}\right)\end{array}$ & $\boldsymbol{i}_{\max (\mathbf{D})}\left(\mathbf{m A} \mathbf{A} / \mathbf{c m}^{2}\right)$ & $\left(\boldsymbol{i}_{\max (\mathbf{H})} \boldsymbol{i}_{\max (\mathbf{D}))^{\mathbf{2}}}\right.$ \\
\hline 0.2 & 0.44 & 0.37 & 1.4 \\
\hline 0.4 & 0.74 & 0.40 & 3.4 \\
\hline 0.7 & 1.03 & 0.48 & 4.6 \\
\hline 1.1 & 1.51 & 0.52 & 8.4 \\
\hline 1.4 & 2.69 & 0.71 & 14.4 \\
\hline 1.8 & 3.27 & 0.78 & 17.6 \\
\hline 2.1 & 5.13 & 1.06 & 23.4 \\
\hline 2.5 & 6.33 & 1.15 & 30.3 \\
\hline 3.1 & 7.51 & 1.50 & 25.1 \\
\hline 5.0 & 9.17 & 3.43 & 7.1 \\
\hline 9.2 & 12.36 & 3.46 & 12.8 \\
\hline 13.8 & 12.92 & 3.23 & 16.0 \\
\hline
\end{tabular}

Table S6. Currents at $-2.70 \mathrm{~V}$ vs Fc ${ }^{+/ 0}$ for $\mathbf{C o L}^{\mathrm{NO2}}$ in $\mathrm{MeCN}$ under an $\mathrm{N}_{2}$ atmosphere generated from titrations with $\mathrm{H}_{2} \mathrm{O}$ and $\mathrm{D}_{2} \mathrm{O}$ and the $\mathrm{H} / \mathrm{D}$ ratio of currents.

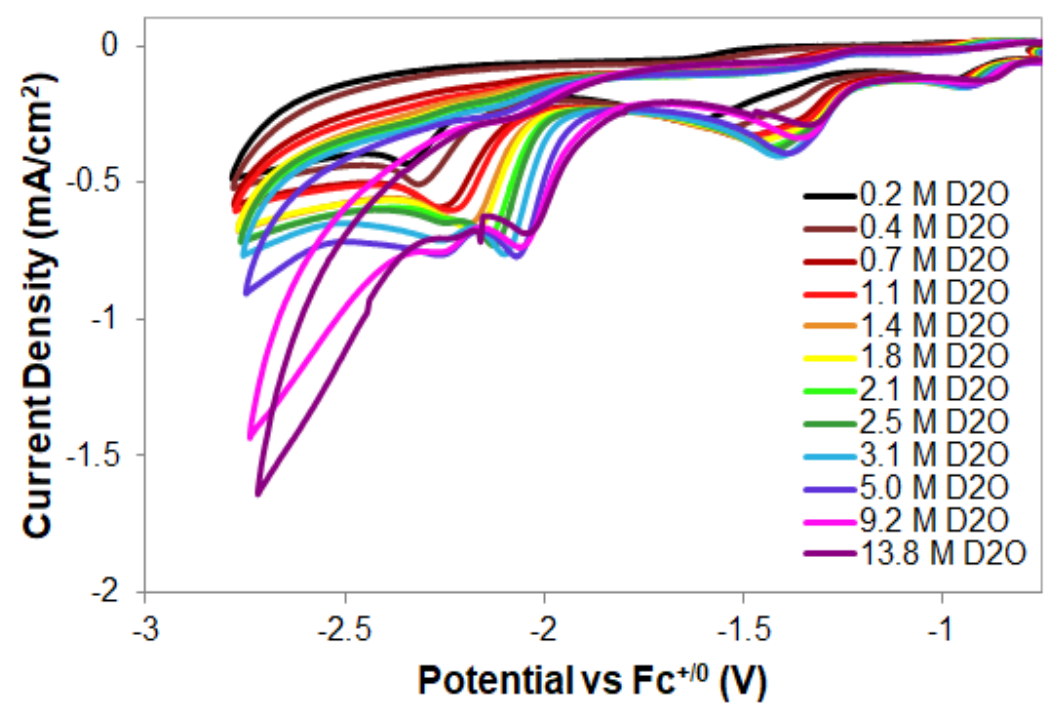

Figure S21. Cyclic voltammograms of $0.5 \mathrm{mM} \mathrm{CoL}^{\mathrm{NO2}}$ in $0.1 \mathrm{M} \mathrm{TBAPF}_{6} \mathrm{MeCN}$ solution under a $\mathrm{CO}_{2}$ atmosphere with increasing amounts of $\mathrm{D}_{2} \mathrm{O}$. Scan rate $=100 \mathrm{mV} / \mathrm{s}$. 


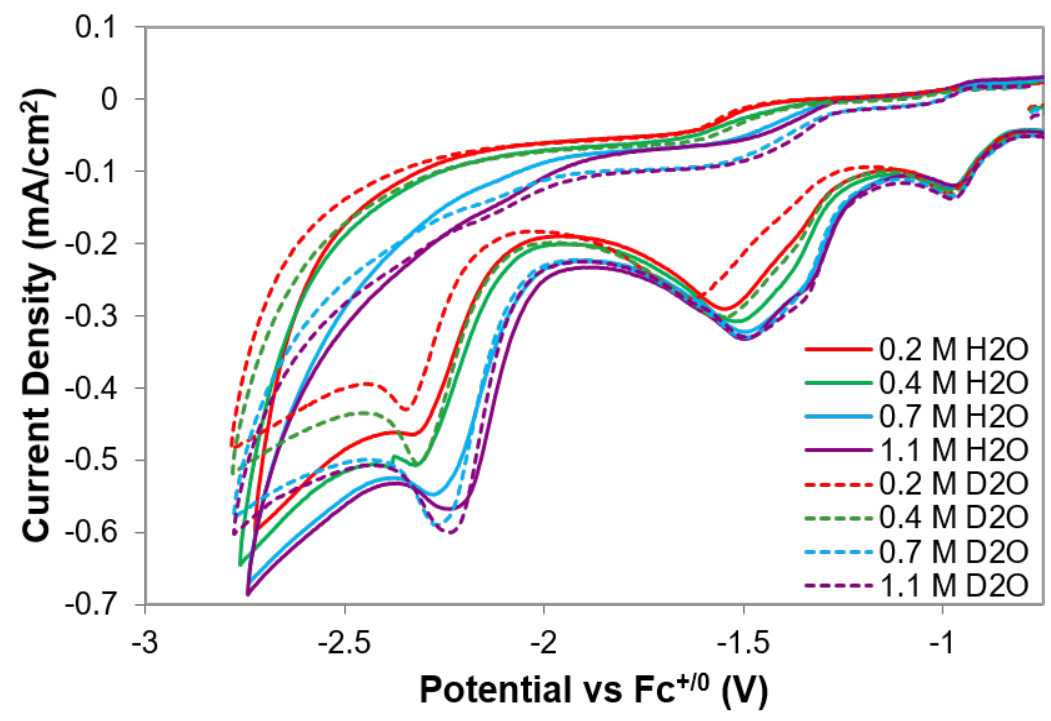

Figure S22. Cyclic voltammograms of $0.5 \mathrm{mM} \mathrm{CoL}^{\mathrm{NO2}}$ in $0.1 \mathrm{M} \mathrm{TBAPF}_{6} \mathrm{MeCN}$ solution under an $\mathrm{CO}_{2}$ atmosphere with increasing amounts of $\mathrm{H}_{2} \mathrm{O}$ (solid lines) and $\mathrm{D}_{2} \mathrm{O}$ (dashed lines). Scan rate $=100 \mathrm{mV} / \mathrm{s}$.

\begin{tabular}{|c|c|c|c|}
\hline [Acid] $(\mathbf{M})$ & $\begin{array}{c}\boldsymbol{i}_{\max (\mathbf{H})} \\
\left(\mathbf{m A} / \mathbf{c m}^{2}\right)\end{array}$ & $\boldsymbol{i}_{\max (\mathbf{D})}\left(\mathbf{m A} \mathbf{A} \mathbf{c m}^{\mathbf{2}}\right)$ & $\left(\boldsymbol{i}_{\max (\mathbf{H})} / \boldsymbol{i}_{\max (\mathbf{D}))^{\mathbf{2}}}\right.$ \\
\hline 0.2 & 0.59 & 0.46 & 1.6 \\
\hline 0.4 & 0.61 & 0.49 & 1.5 \\
\hline 0.7 & 0.65 & 0.55 & 1.4 \\
\hline 1.1 & 0.66 & 0.56 & 1.4 \\
\hline 1.4 & 0.75 & 0.64 & 1.4 \\
\hline 1.8 & 0.90 & 0.64 & 2.0 \\
\hline 2.1 & 1.03 & 0.68 & 2.3 \\
\hline 2.5 & 1.24 & 0.69 & 3.2 \\
\hline 3.1 & 1.30 & 0.73 & 3.2 \\
\hline 5.0 & 1.89 & 0.85 & 4.9 \\
\hline 9.2 & 3.27 & 1.36 & 5.8 \\
\hline 13.8 & 4.38 & 1.60 & 7.5 \\
\hline
\end{tabular}

Table S7. Currents at $-2.70 \mathrm{~V}$ vs Fc ${ }^{+/ 0}$ for $\mathbf{C o L} \mathbf{L}^{\mathrm{NO} 2}$ in $\mathrm{MeCN}$ under a $\mathrm{CO}_{2}$ atmosphere generated from titrations with $\mathrm{H}_{2} \mathrm{O}$ and $\mathrm{D}_{2} \mathrm{O}$ and the $\mathrm{H} / \mathrm{D}$ ratio of currents. 


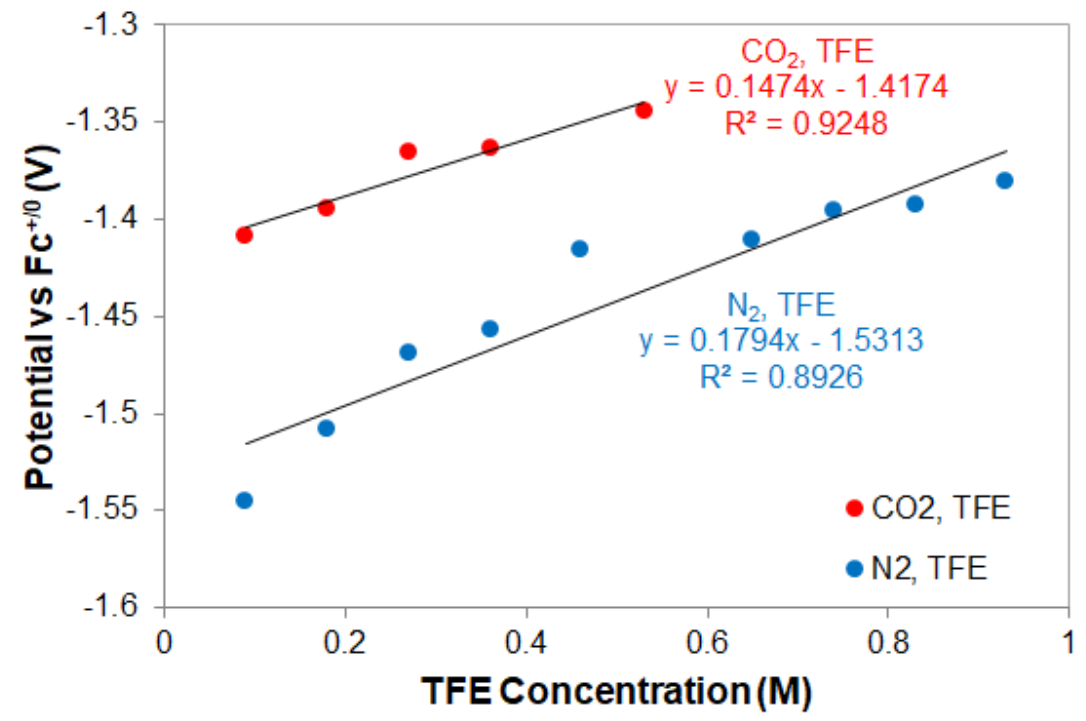

Figure S23. Plot of the anodically shifted reduction feature $\left(-1.75 \mathrm{~V} @ 0 \mathrm{M}\right.$ TFE) for $\mathbf{C o L}^{\mathrm{NO2}}$ vs TFE concentration under $\mathrm{N}_{2}$ (blue) and $\mathrm{CO}_{2}$ (red).

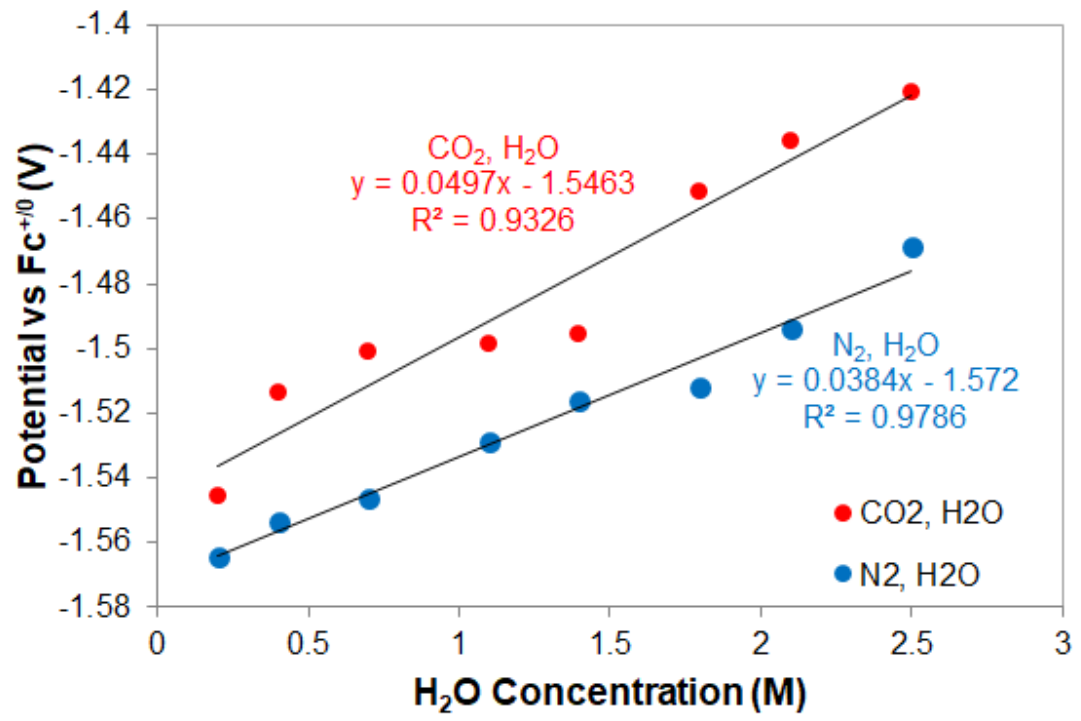

Figure S24. Plot of the anodically shifted reduction feature $\left(-1.75 \mathrm{~V} @ 0\right.$ M TFE) for $\mathbf{C o L}^{\mathrm{NO2}}$ vs $\mathrm{H}_{2} \mathrm{O}$ concentration under $\mathrm{N}_{2}$ (blue) and $\mathrm{CO}_{2}$ (red). 


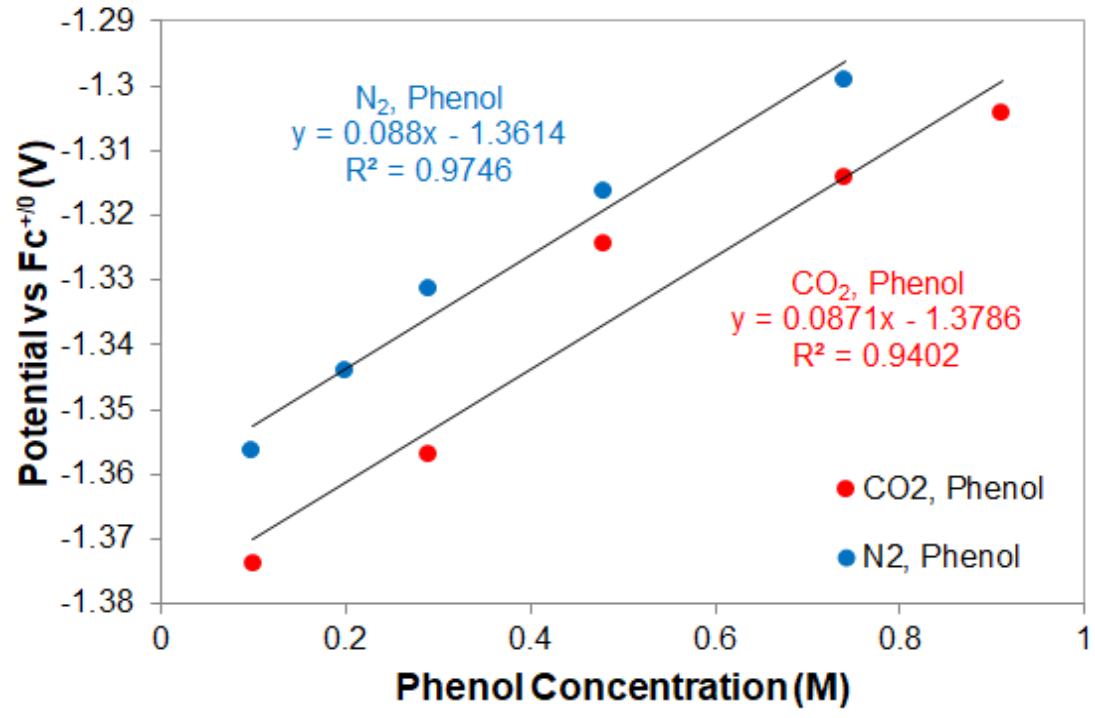

Figure S25. Plot of the anodically shifted reduction feature $\left(-1.75 \mathrm{~V} @ 0 \mathrm{M}\right.$ TFE) for $\mathbf{C o L}^{\mathrm{NO2}}$ vs phenol concentration under $\mathrm{N}_{2}$ (blue) and $\mathrm{CO}_{2}$ (red).

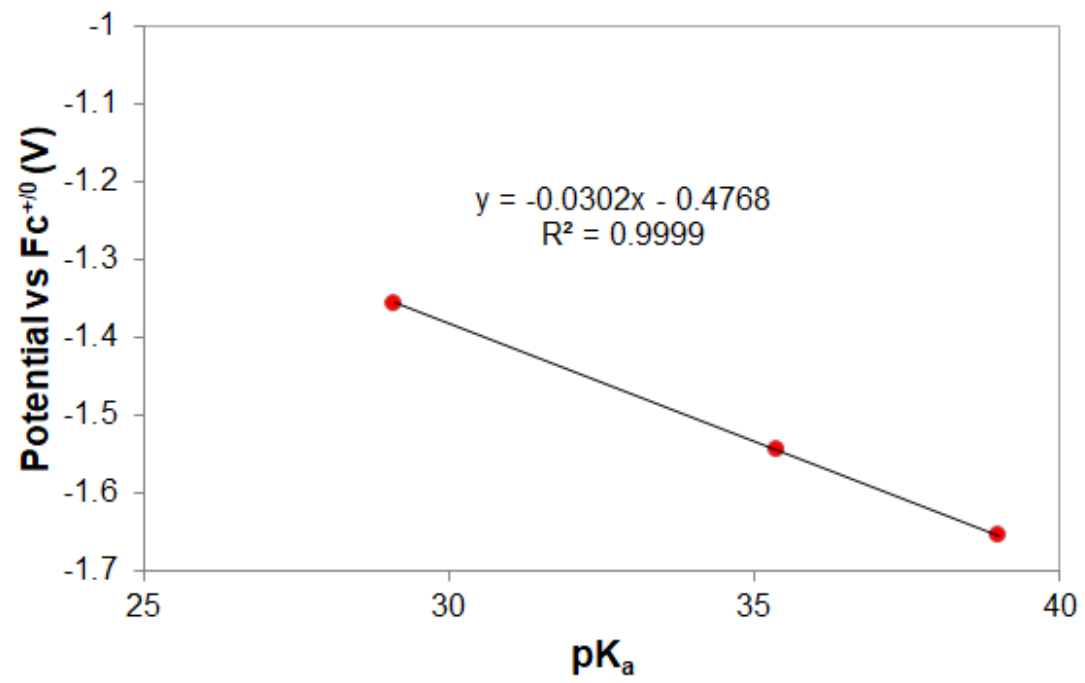

Figure S26. Plot of potential vs $\mathrm{pK}_{\mathrm{a}}$ for $\mathbf{C o L}^{\mathrm{NO2}}$ under $\mathrm{N}_{2}$ based on the shift of the reduction feature at $-1.75 \mathrm{~V}$ vs $\mathrm{Fc}^{+/ 0}$ when titrated with water, TFE, and phenol. 


\begin{tabular}{|c|c|c|}
\hline Acid & pKa & Ref \\
\hline $\mathrm{H}_{2} \mathrm{O}$ & $38-41$ & 6 \\
\hline $\mathrm{TFE}$ & 35.8 & 7 \\
\hline $\mathrm{PhOH}$ & 29.1 & 8 \\
\hline $\mathrm{H}_{2} \mathrm{CO}_{3}$ & 23.4 & 9 \\
\hline
\end{tabular}

Table S11. $\mathrm{p} K_{a}$ values of pertinent acids used in this study.

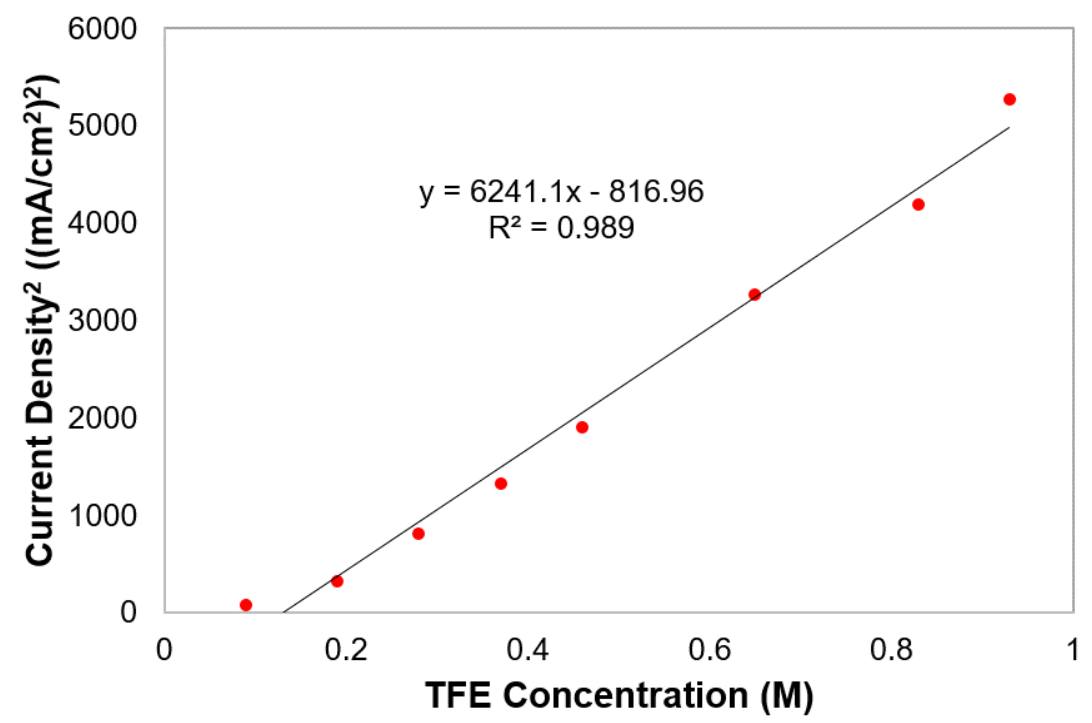

Figure S27. Plot of current density ${ }^{2}$ vs TFE concentration for $\mathbf{C o L}^{\mathbf{N O 2}}$ in $\mathrm{MeCN}$ solution under $\mathrm{N}_{2}$ with increasing amounts of TFE. Current was measured at $-2.70 \mathrm{~V}$ vs $\mathrm{Fc}^{+/ 0}$ for all concentrations. 


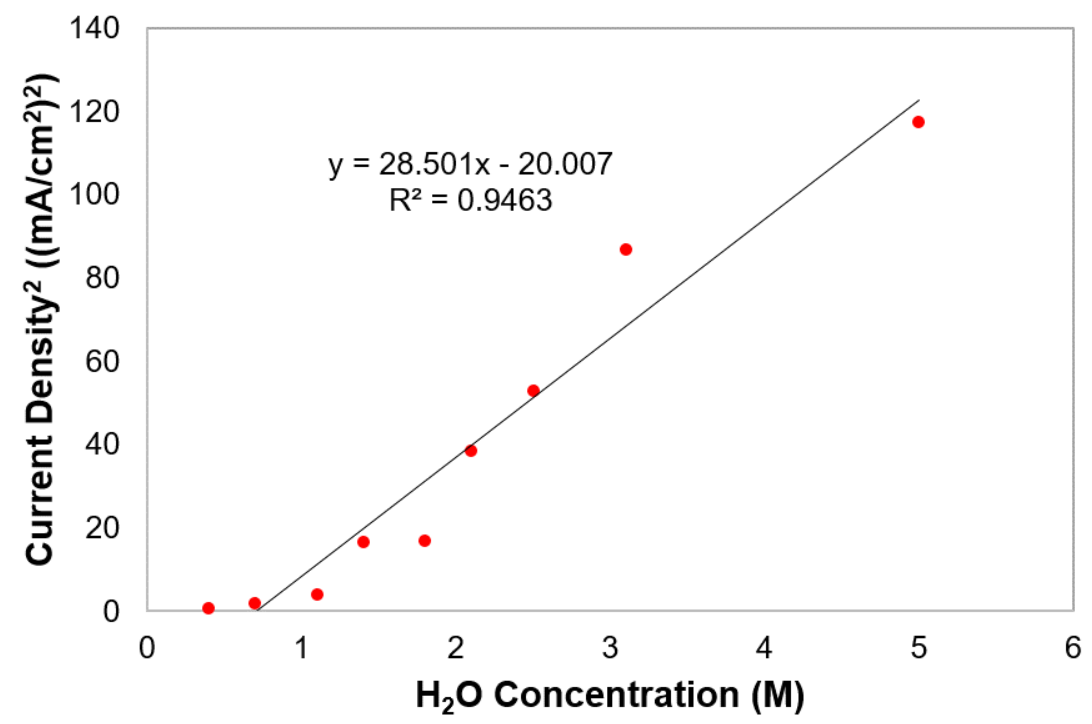

Figure S28. Plot of current density ${ }^{2}$ vs $\mathrm{H}_{2} \mathrm{O}$ concentration for $\mathbf{C o L}^{\mathbf{N O 2}}$ in $\mathrm{MeCN}$ solution under $\mathrm{N}_{2}$ with increasing amounts of $\mathrm{H}_{2} \mathrm{O}$. Current was measured at $-2.70 \mathrm{~V}$ vs $\mathrm{Fc}^{+/ 0}$ for all concentrations.

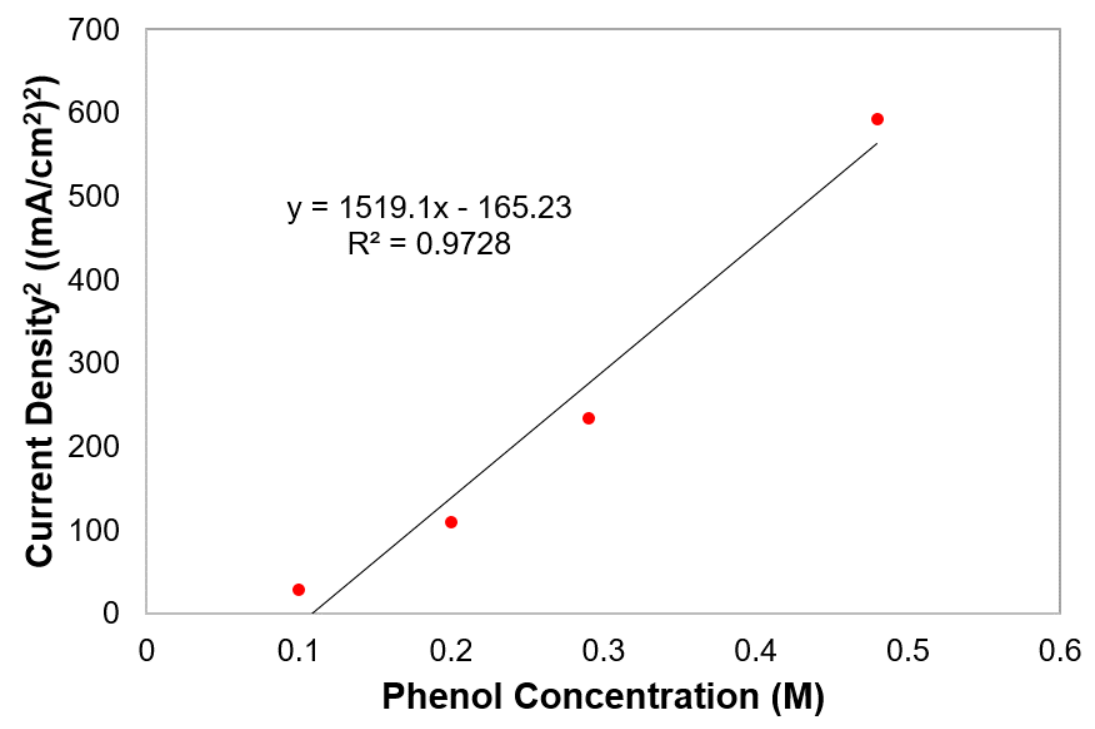

Figure S29. Plot of current density ${ }^{2}$ vs $\mathrm{PhOH}$ concentration for $\mathbf{C o L}^{\mathbf{N O 2}}$ in $\mathrm{MeCN}$ solution under $\mathrm{N}_{2}$ with increasing amounts of phenol. Current was measured at $-2.70 \mathrm{~V} \mathrm{vs} \mathrm{Fc}^{+/ 0}$ for all concentrations. 


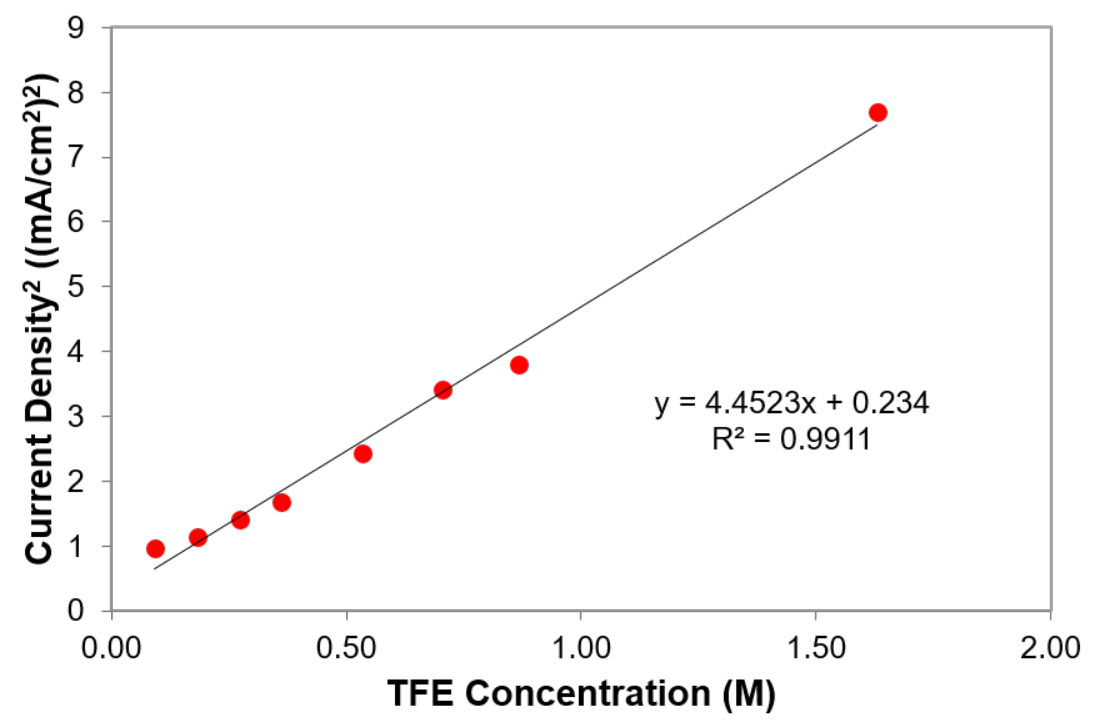

Figure S30. Plot of current density ${ }^{2}$ vs TFE concentration for $\mathbf{C o L}^{\mathbf{N O 2}}$ in $\mathrm{MeCN}$ solution under $\mathrm{CO}_{2}$ with increasing amounts of TFE. Current was measured at $-2.70 \mathrm{~V} \mathrm{vs} \mathrm{Fc}^{+/ 0}$ for all concentrations.

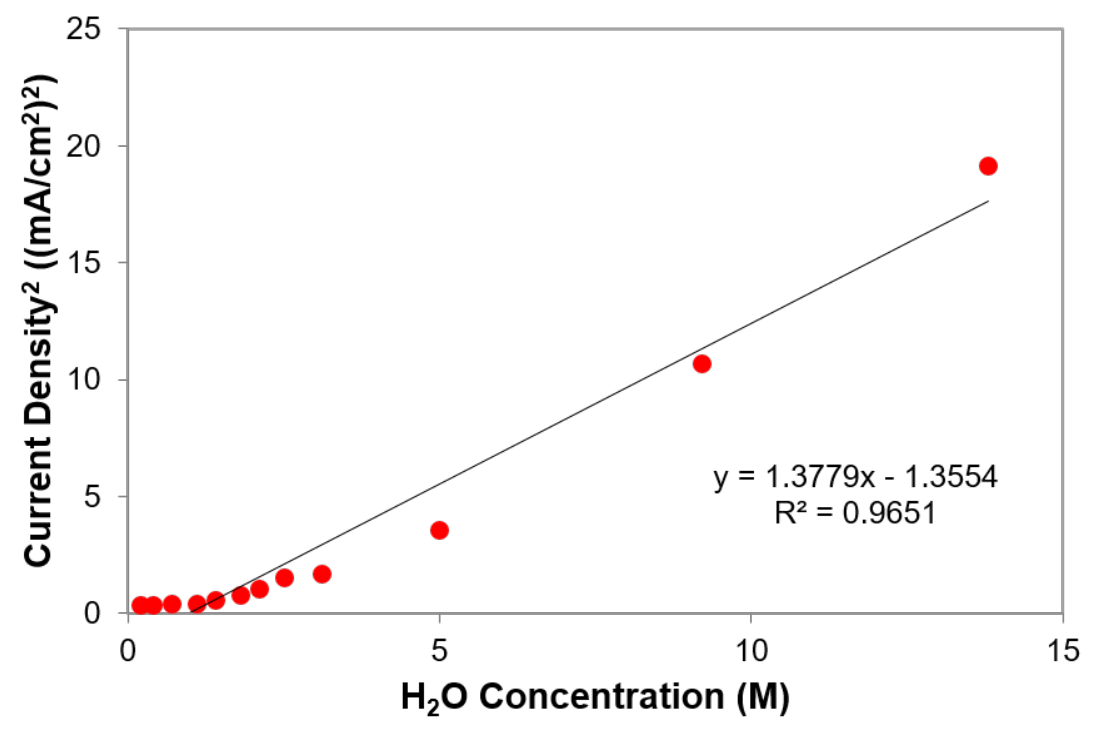

Figure S31. Plot of current density ${ }^{2}$ vs $\mathrm{H}_{2} \mathrm{O}$ concentration for $\mathbf{C o L}^{\mathbf{N O 2}}$ in $\mathrm{MeCN}$ solution under $\mathrm{CO}_{2}$ with increasing amounts of $\mathrm{H}_{2} \mathrm{O}$. Current was measured at $-2.70 \mathrm{~V}$ vs $\mathrm{Fc}^{+/ 0}$ for all concentrations. 


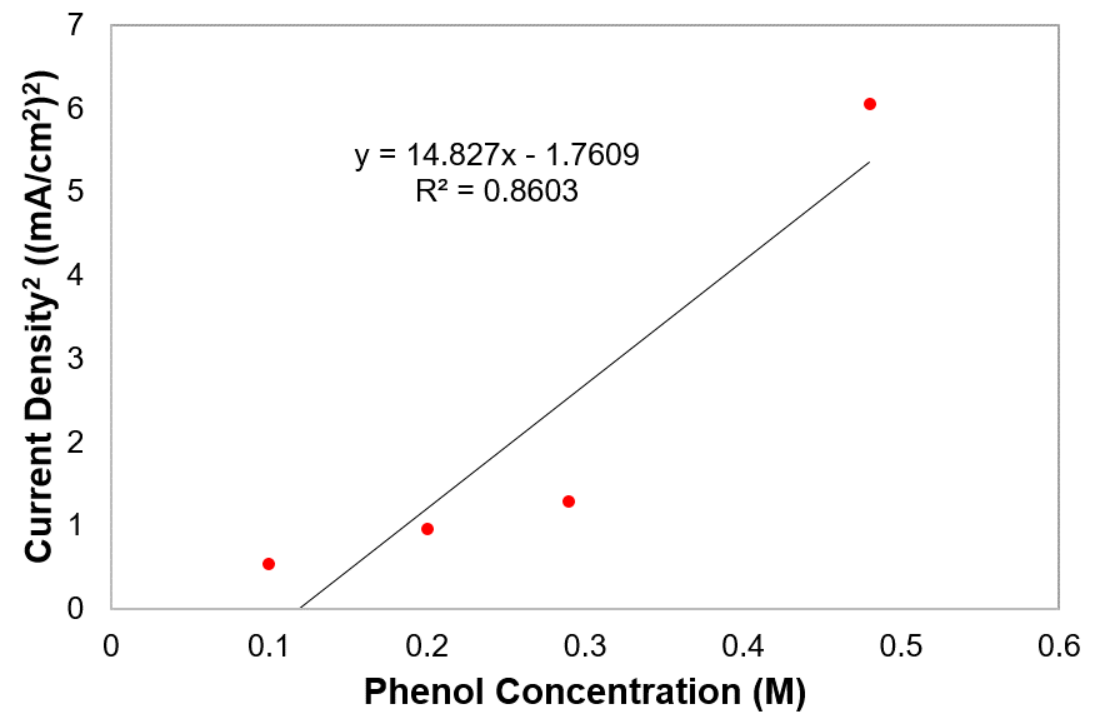

Figure S32. Plot of current density ${ }^{2}$ vs $\mathrm{PhOH}$ concentration for $\mathbf{C o L}^{\mathbf{N O 2}}$ in $\mathrm{MeCN}$ solution under $\mathrm{CO}_{2}$ with increasing amounts of phenol. Current was measured at $-2.70 \mathrm{~V}$ vs $\mathrm{Fc}^{+/ 0}$ for all concentrations.

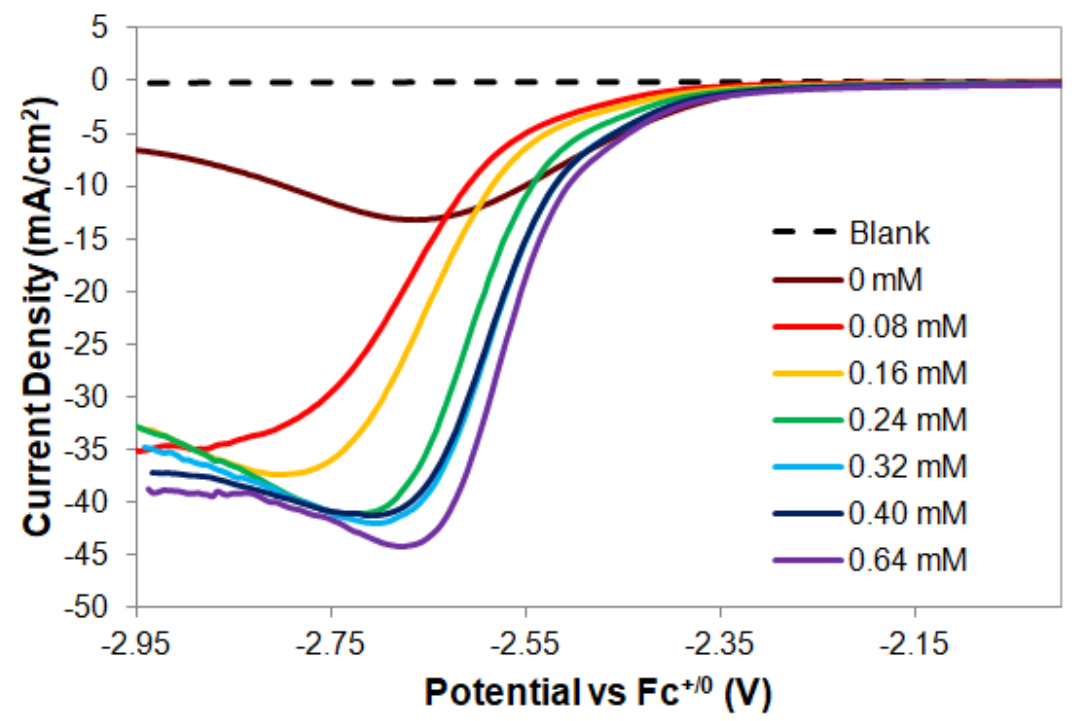

Figure S33. Cyclic voltammograms of $0.1 \mathrm{M} \mathrm{TBAPF}_{6}$ acetonitrile solution under $\mathrm{N}_{2}$ with $0.5 \mathrm{M}$ TFE, and with increasing amounts of $\mathrm{CoL}^{\mathrm{NO2}}$. 


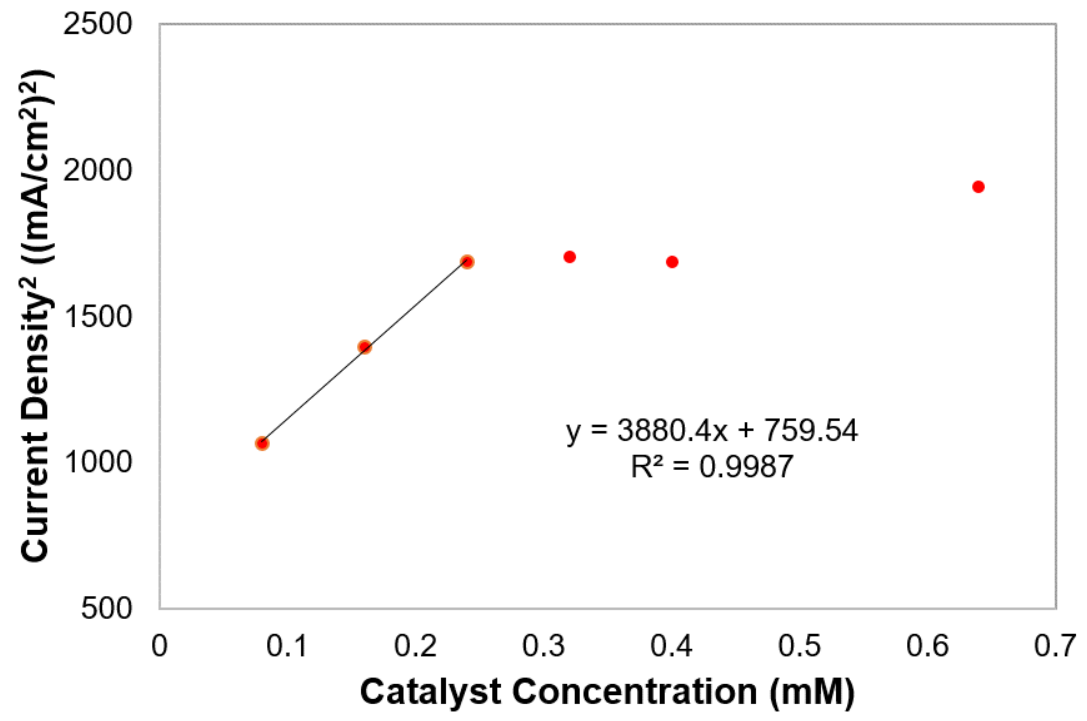

Figure S34. Current density ${ }^{2}$ vs catalyst concentration for $\mathrm{CoL}^{\mathrm{NO2}}$.

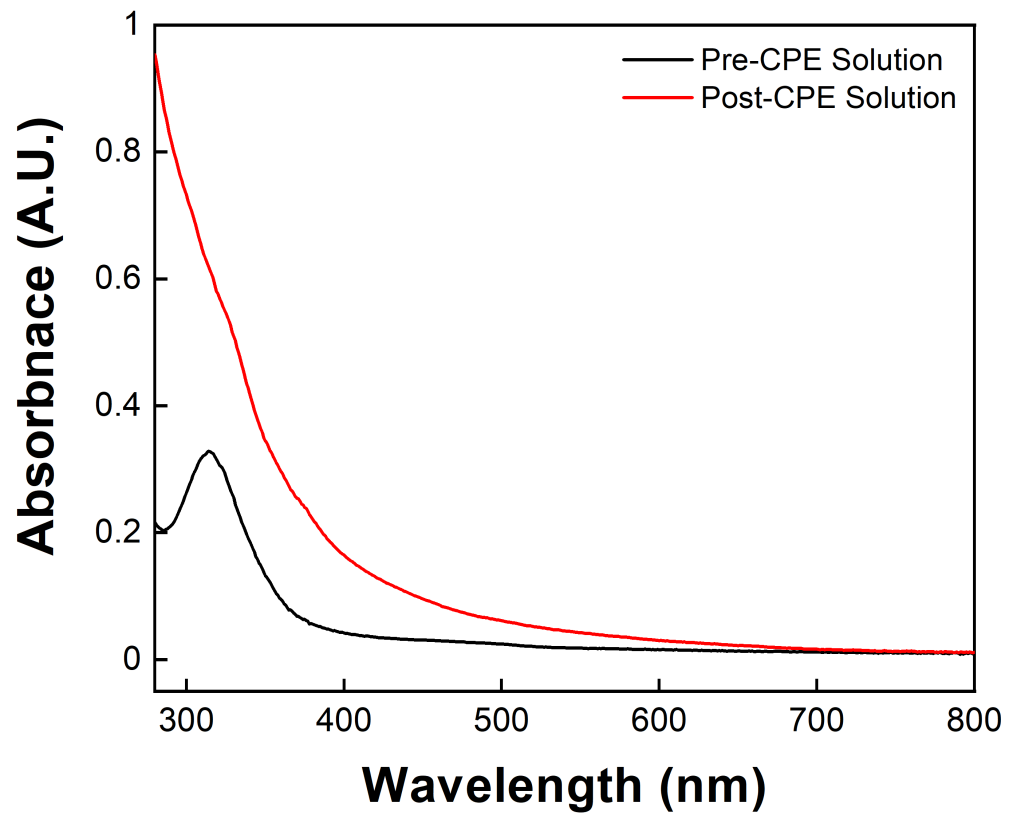

Figure S35. UV-vis spectrum in acetonitrile of the pre- and post-CPE solution of $\mathbf{C o L}^{\mathrm{NO2}}(0.5$ $\mathrm{mM})$ with TFE $(0.4 \mathrm{M})$ under $\mathrm{N}_{2}(1 \mathrm{~atm})$. The solution was prepared by injecting $0.1 \mathrm{~mL}$ of the working solution into $2.9 \mathrm{~mL}$ of pure acetonitrile under an $\mathrm{N}_{2}$ atmosphere. 


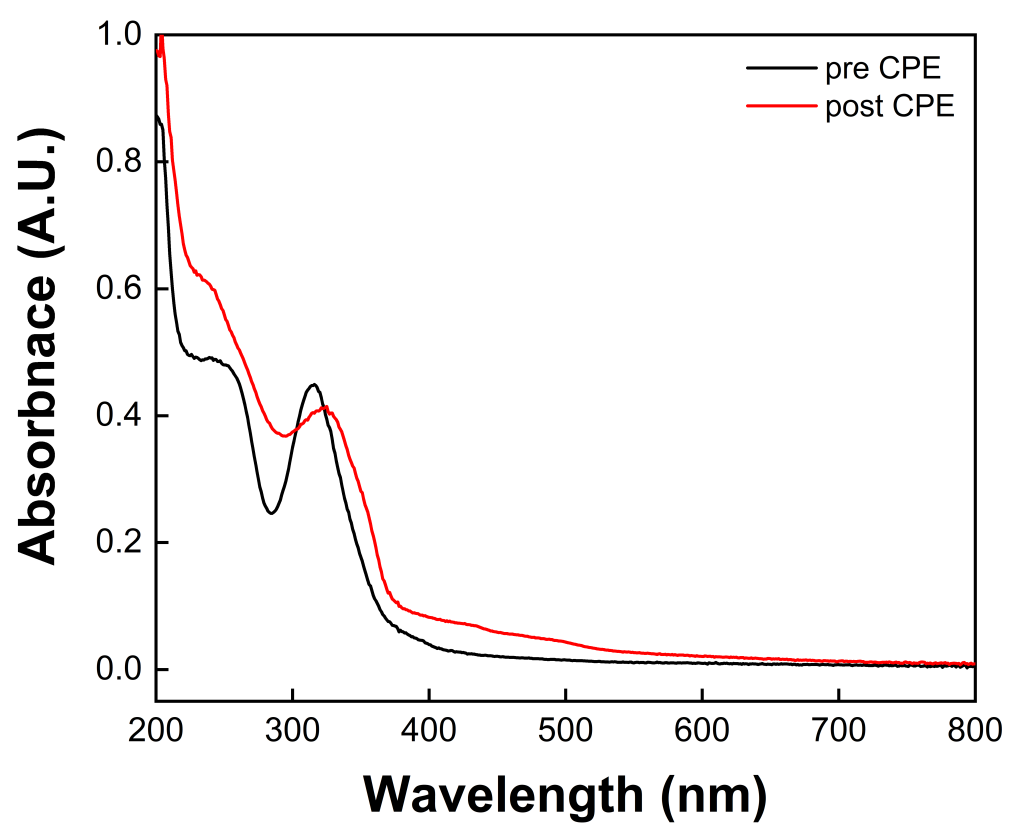

Figure S36. UV-vis spectrum in acetonitrile of the pre- and post-CPE solution of $\mathbf{C o L}^{\mathrm{NO2}}(0.5$ $\mathrm{mM})$ with TFE $(1 \mathrm{M})$ under $\mathrm{CO}_{2}(1 \mathrm{~atm})$. The solution was prepared by injecting $0.1 \mathrm{~mL}$ of the working solution into $2.9 \mathrm{~mL}$ of pure acetonitrile under an $\mathrm{N}_{2}$ atmosphere. An observed redshift from $315 \mathrm{~nm}$ to $324 \mathrm{~nm}$ is present following electrolysis.

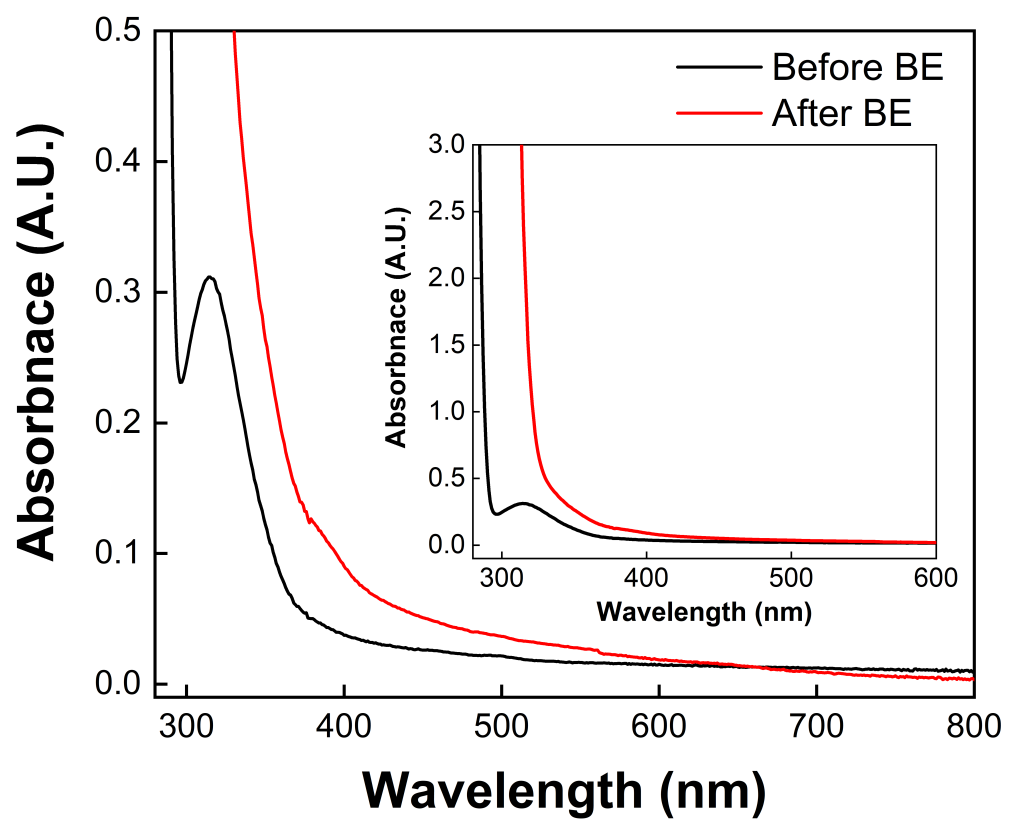

Figure S37. UV-vis spectrum in acetonitrile of the pre- and post-CPE solution of $\mathbf{C o L}^{\mathrm{NO2}}(0.5$ $\mathrm{mM})$ with Phenol $(1 \mathrm{M})$ under $\mathrm{CO}_{2}$ (1 atm). The solution was prepared by injecting $0.1 \mathrm{~mL}$ of the working solution into $2.9 \mathrm{~mL}$ of pure acetonitrile under an $\mathrm{N}_{2}$ atmosphere. 


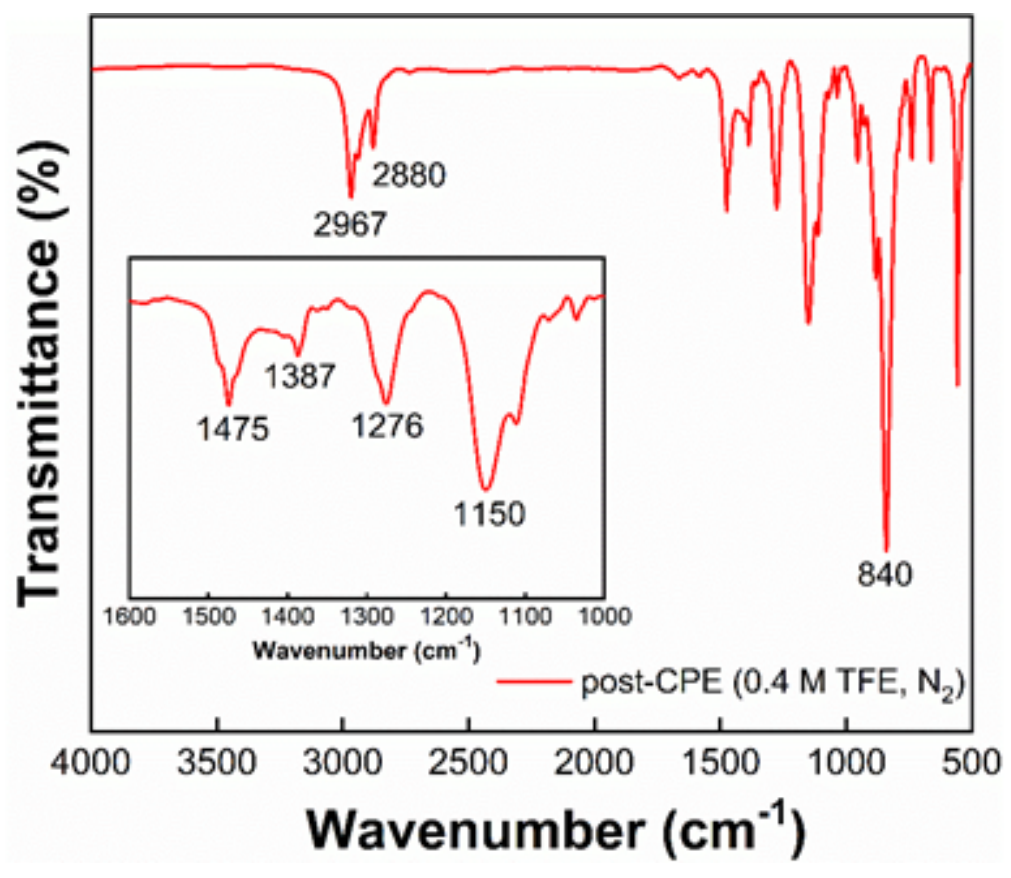

Figure S38. FTIR spectrum of the working compartment solution following 24 hours of electrolysis with TFE $(0.4 \mathrm{M})$ under $\mathrm{N}_{2}(1 \mathrm{~atm})$. The labeled features primarily correlate to the electrolyte, which is in large excess relative to $\mathbf{C o}^{\mathbf{L N O 2}}$. The sample was prepared as a $\mathrm{KBr}$ pellet by drying the working compartment solution under vacuum and mixing the resulting residue with $\mathrm{KBr}$ in an $\mathrm{N}_{2}$ filled dry box. 


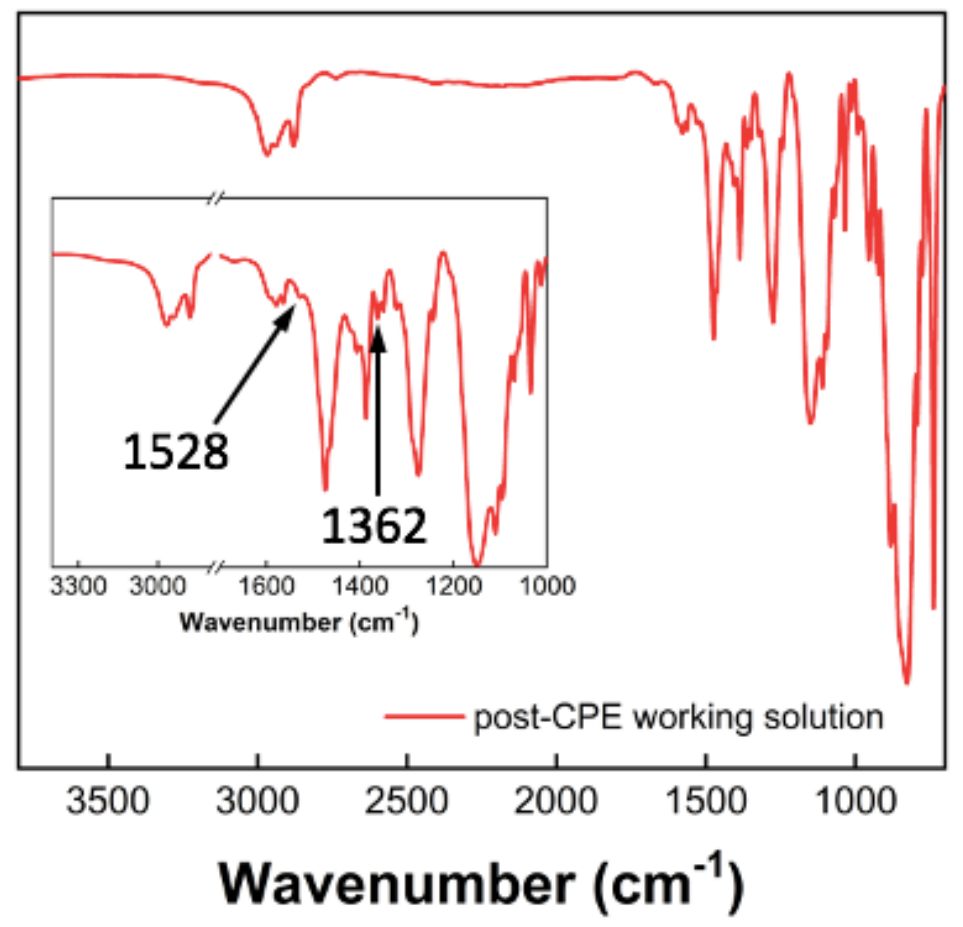

Figure S39. FTIR spectrum of the working compartment solution following 24 hours of electrolysis with TFE $(1 \mathrm{M})$ under $\mathrm{CO}_{2}(1 \mathrm{~atm})$. The weakly resolved features at 1528 and 1362 $\mathrm{cm}^{-1}$ are ascribed to the nitro group present in $\mathbf{C o}^{\mathbf{L N O 2}}$. The sample was prepared as a KBr pellet by drying the working compartment solution under vacuum and mixing the resulting residue with $\mathrm{KBr}$ in an $\mathrm{N}_{2}$ filled dry box. 


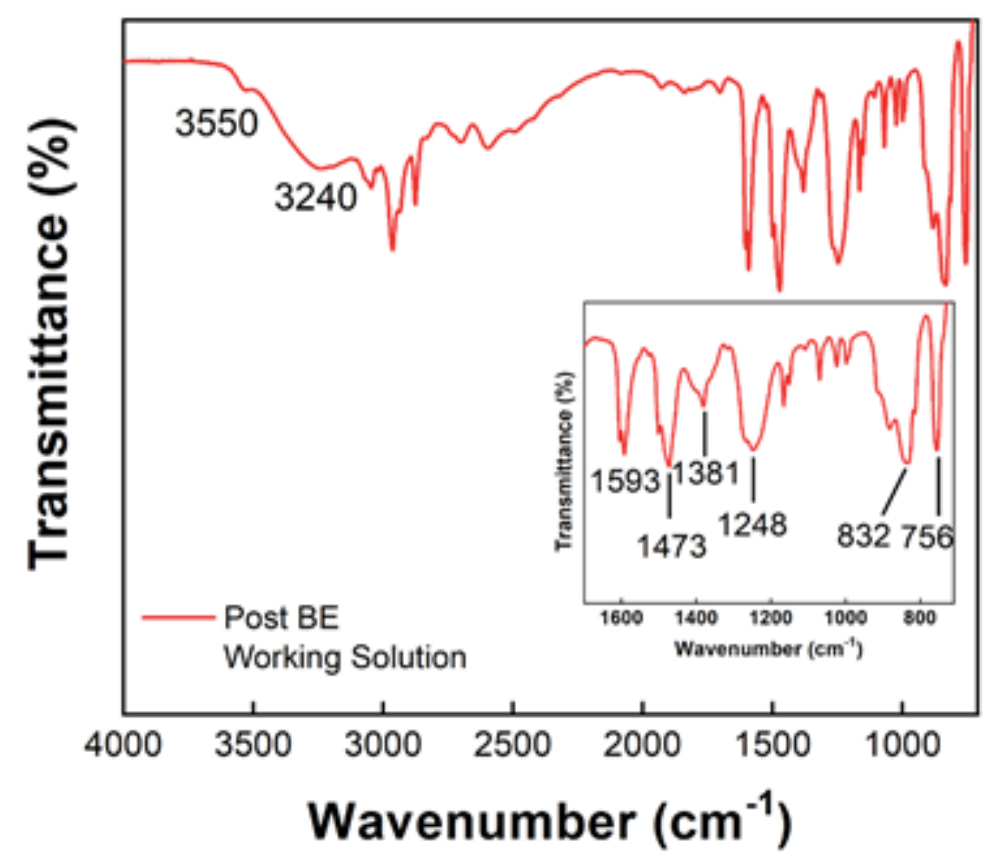

Figure S40. FTIR spectrum of the working compartment solution following 24 hours of electrolysis with Phenol $(1 \mathrm{M})$ under $\mathrm{CO}_{2}(1 \mathrm{~atm})$. The labeled features primarily correlate to the electrolyte and phenol, which are in large excess relative to $\mathbf{C o}^{\mathbf{L N O 2}}$. The sample was prepared as a $\mathrm{KBr}$ pellet by drying the working compartment solution under vacuum and mixing the resulting residue with $\mathrm{KBr}$ in an $\mathrm{N}_{2}$ filled dry box.
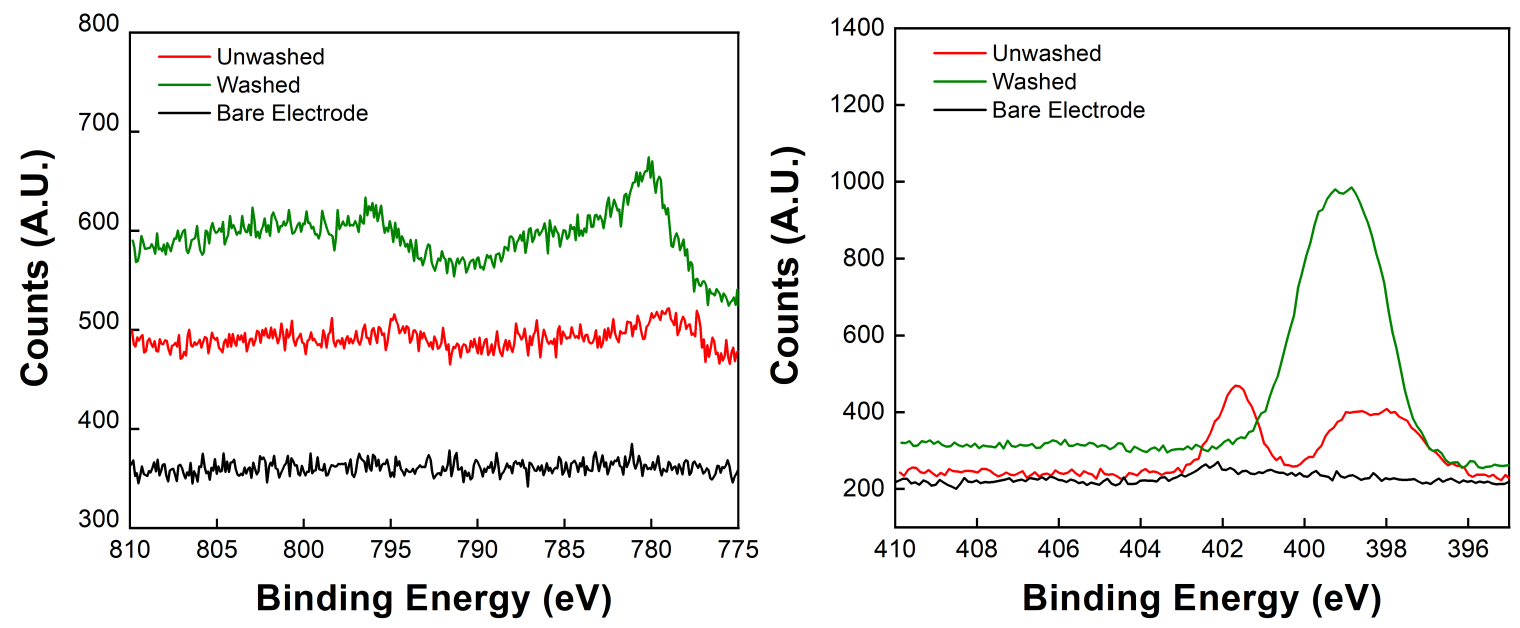

Figure S41. XPS spectra of the post-CPE working electrode $\left(0.5 \mathrm{mM} \mathrm{CoL}^{\mathrm{NO}}, 0.4 \mathrm{M}\right.$ TFE and $0.1 \mathrm{M}\left[n \mathrm{Bu}_{4} \mathrm{~N}\right]\left[\mathrm{PF}_{6}\right]$ under an $\mathrm{N}_{2}$ atmosphere) Co $2 \mathrm{p}$ (left) and $\mathrm{N}$ 1s (right) regions. The asprepared sample is collected from the post-CPE electrode without washing with any solvent. The washed sample spectrum is collected from rinsing $(\times 3)$ the post-CPE as-prepared electrode with 
pure acetonitrile. The increase in the cobalt and nitrogen XPS signal is interpreted as electrolyte $\left(n \mathrm{Bu}_{4} \mathrm{NPF}_{6}\right)$ being washed away to expose the surface deposited material.
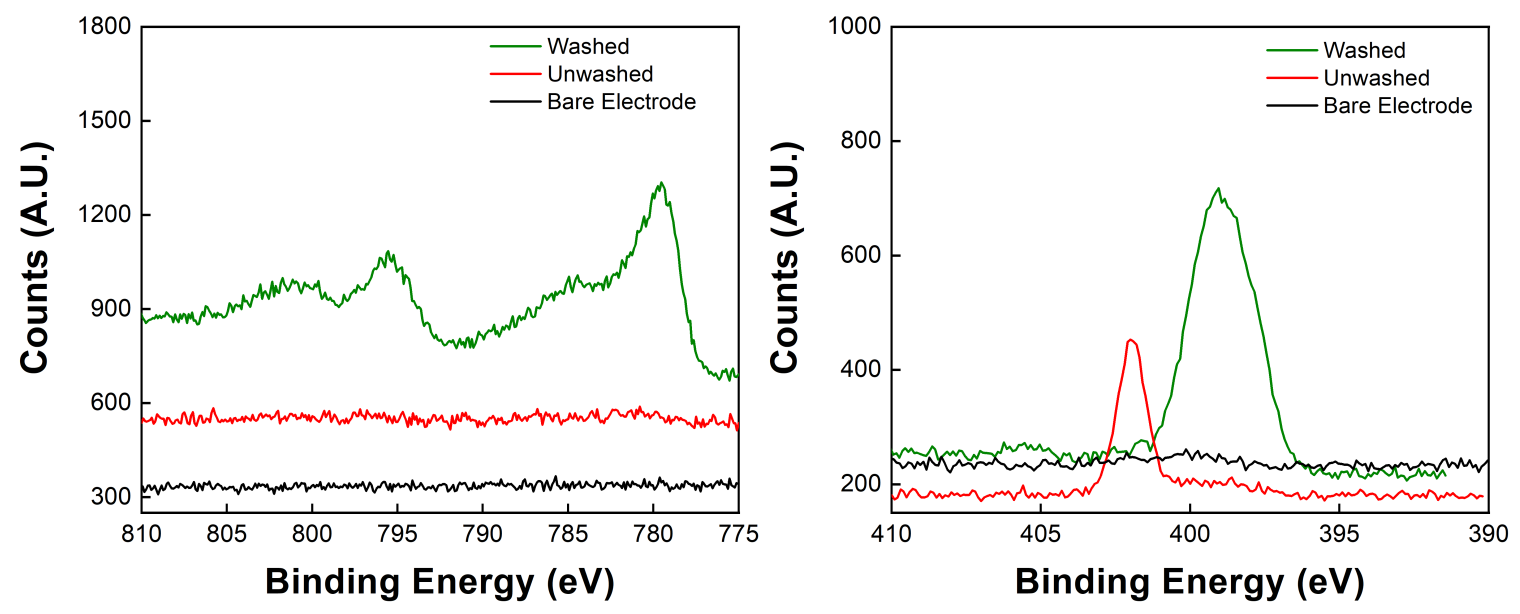

Figure S42. XPS spectra of the post-CPE working electrode $\left(0.5 \mathrm{mM} \mathrm{CoL}^{\mathrm{NO}}, 1 \mathrm{M}\right.$ TFE and 0.1 $\mathrm{M}\left[n \mathrm{Bu}_{4} \mathrm{~N}\right]\left[\mathrm{PF}_{6}\right]$ under an $\mathrm{CO}_{2}$ atmosphere) $\mathrm{Co} 2 \mathrm{p}$ (left) and $\mathrm{N} 1 \mathrm{~s}$ (right) regions. The asprepared sample is collected from the post-CPE electrode without washing with any solvent. The washed sample spectrum is collected from rinsing $(\times 3)$ the post-CPE as-prepared electrode with pure acetonitrile. The increase in the cobalt and nitrogen XPS signal is interpreted as electrolyte $\left(n \mathrm{Bu}_{4} \mathrm{NPF}_{6}\right)$ being washed away to expose the surface deposited material. 


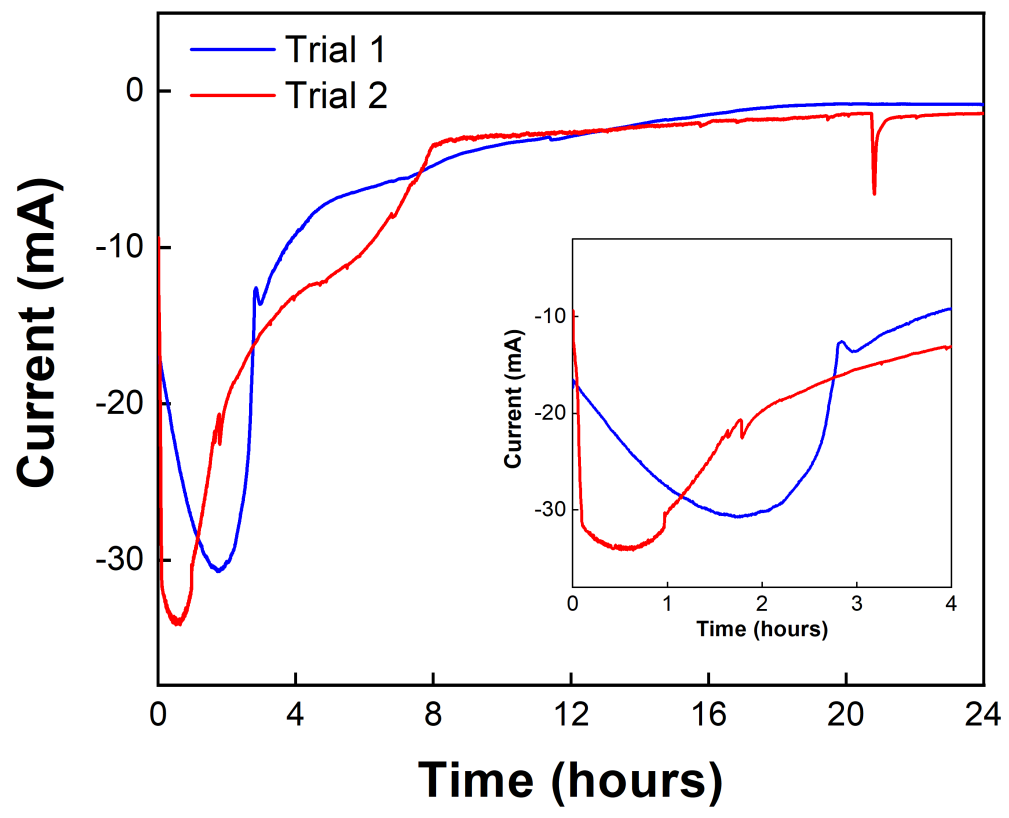

Figure S43. Replicate CPE experiment of $\mathbf{C o L}^{\mathrm{NO2}}(0.5 \mathrm{mM})$ with phenol $(1 \mathrm{M})$ under a $\mathrm{CO}_{2}$ atmosphere (Trial 2). Trial 1 is taken from the phenol trace in Figure 6, and is overlayed with the replicate trial to demonstrate the variability of the initial "incubation behavior" suggestive of a heterogeneous phenomenon.

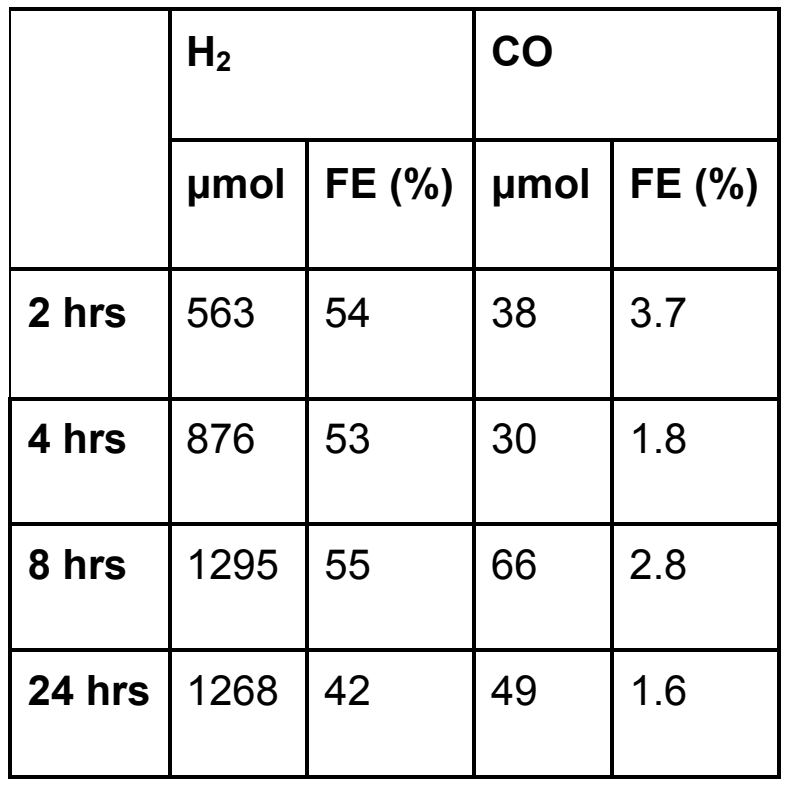

Table S12. Results of a replicate experiment of a 24 hour controlled potential electrolysis of 0.5 $\mathrm{mM} \mathrm{CoL}{ }^{\mathrm{NO} 2}$ in acetonitrile under $\mathrm{CO}_{2}$ with $1 \mathrm{M} \mathrm{PhOH}$ and $0.1 \mathrm{M} \mathrm{TBAPF}_{6}$ at $-2.70 \mathrm{~V} \mathrm{vs} \mathrm{Fc}^{+/ 0}$. 


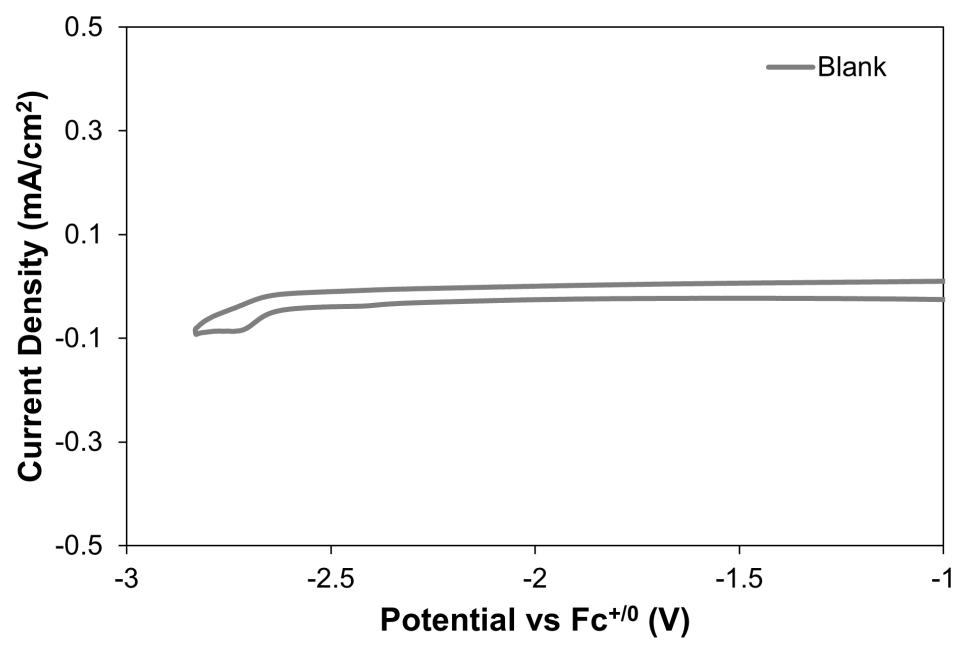

Figure S44. Cyclic voltammogram of a blank acetonitrile solution containing only electrolyte $0.1 \mathrm{M} \mathrm{NBu}_{4} \mathrm{PF}_{6}$ and ferrocene as an internal reference (ferrocene couple not shown). A glassy carbon working electrode, platinum counter electrode and a silver wire pseudo-reference electrode were used. A minor feature is present at approximately $-2.7 \mathrm{~V} v s . \mathrm{Fc}^{+/ 0}$ and is attributed to a solvent-glassy carbon interaction.

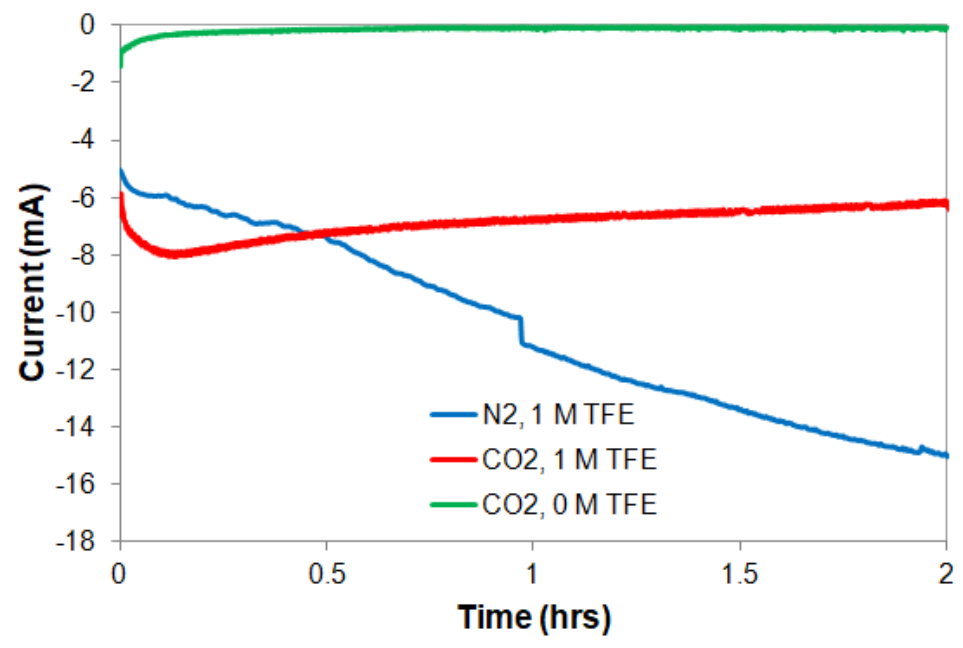

Figure S45. Bulk electrolysis of $\mathbf{C o L}^{\text {NO2 }}$ in DMF with $1 \mathrm{M}$ TFE under $\mathrm{N}_{2}$ (blue), $1 \mathrm{M}$ TFE under $\mathrm{CO}_{2}$ (red), and $0 \mathrm{M}$ TFE under $\mathrm{CO}_{2}$ (green). $\left[\mathrm{CoL}^{\mathrm{NO}}\right]=0.5 \mathrm{mM}$. Scan rates $=100 \mathrm{mV} / \mathrm{s}$. 
Table S13. Results of 2 hour controlled potential electrolysis of $0.5 \mathrm{mM} \mathrm{CoL}{ }^{\mathrm{NO2}}$ in DMF with $0.1 \mathrm{M} \mathrm{TBAPF}_{6}$ and with varied atmospheres and TFE concentrations. The production of CO in the absence of $\mathrm{CO}_{2}$ is likely caused by the deformylation of DMF.

\begin{tabular}{|c|c|c|c|c|}
\hline & \multicolumn{2}{|c|}{$\mathbf{H}_{2}$} & \multicolumn{2}{c|}{ CO } \\
\cline { 2 - 5 } & $\boldsymbol{\mu m o l}$ & FE (\%) & $\boldsymbol{\mu m o l}$ & FE (\%) \\
\hline $\mathrm{N}_{2}, \mathbf{1} \mathrm{M}$ TFE & 311 & 73 & 4 & $<1$ \\
\hline $\mathrm{CO}_{2}, \mathbf{1} \mathrm{M}$ TFE & 167 & 65 & 5 & 2 \\
\hline $\mathrm{CO}_{2}, \mathbf{0} \mathrm{M}$ TFE & 0 & 0 & 0 & 0 \\
\hline
\end{tabular}

Table S14. Sample and crystal data for $\mathrm{CoL}^{\mathrm{NO2}}$.

\begin{tabular}{|c|c|c|}
\hline Chemical formula & \multicolumn{2}{|l|}{$\mathrm{C}_{35} \mathrm{H}_{34} \mathrm{Cl}_{2} \mathrm{CoN}_{12} \mathrm{O}_{10}$} \\
\hline Formula weight & \multicolumn{2}{|l|}{$912.57 \mathrm{~g} / \mathrm{mol}$} \\
\hline Temperature & \multicolumn{2}{|l|}{$100(2) \mathrm{K}$} \\
\hline Wavelength & \multicolumn{2}{|l|}{$0.71073 \AA$} \\
\hline Crystal size & \multicolumn{2}{|c|}{$0.077 \times 0.132 \times 0.270 \mathrm{~mm}$} \\
\hline Crystal habit & \multicolumn{2}{|l|}{ yellow prism } \\
\hline Crystal system & \multicolumn{2}{|l|}{ triclinic } \\
\hline Space group & \multicolumn{2}{|l|}{$P \overline{1}$} \\
\hline \multirow[t]{3}{*}{ Unit cell dimensions } & $a=12.0282(14) \AA$ & $\alpha=73.002(2)^{\circ}$ \\
\hline & $b=12.5514(15) \AA$ & $\beta=70.196(2)^{\circ}$ \\
\hline & $c=15.9811(19) \AA$ & $\gamma=65.433(2)^{\circ}$ \\
\hline Volume & \multicolumn{2}{|l|}{$2031.9(4) \AA^{3}$} \\
\hline $\mathrm{Z}$ & \multicolumn{2}{|l|}{2} \\
\hline Density (calculated) & \multicolumn{2}{|l|}{$1.492 \mathrm{~g} / \mathrm{cm}^{3}$} \\
\hline Absorption coefficient & \multicolumn{2}{|l|}{$0.625 \mathrm{~mm}^{-1}$} \\
\hline $\mathrm{F}(000)$ & \multicolumn{2}{|l|}{938} \\
\hline Diffractometer & \multicolumn{2}{|l|}{ Bruker APEX DUO } \\
\hline Radiation source & \multicolumn{2}{|c|}{ fine-focus tube (MoK $\alpha, \lambda=0.71073 \AA)$} \\
\hline Theta range for data collection & \multicolumn{2}{|c|}{1.81 to $26.37^{\circ}$} \\
\hline Index ranges & \multicolumn{2}{|c|}{$-15 \leq h \leq 15,-15 \leq k \leq 15,-19 \leq l \leq 19$} \\
\hline Reflections collected & \multicolumn{2}{|c|}{35503} \\
\hline Independent reflections & \multicolumn{2}{|c|}{$8246[R($ int $)=0.0620]$} \\
\hline Absorption correction & \multicolumn{2}{|c|}{ multi-scan } \\
\hline Max. and min. transmission & \multicolumn{2}{|l|}{0.9530 and 0.8490} \\
\hline Structure solution technique & \multicolumn{2}{|l|}{ direct methods } \\
\hline Structure solution program & \multicolumn{2}{|c|}{ SHELXTL XT 2014/5 (Bruker AXS, 2014) } \\
\hline Refinement method & \multicolumn{2}{|c|}{ Full-matrix least-squares on $F^{2}$} \\
\hline Refinement program & \multicolumn{2}{|c|}{ SHELXTL XL 2018/3 (Bruker AXS, 2018) } \\
\hline
\end{tabular}




$\begin{array}{ll}\text { Function minimized } & \Sigma \mathrm{w}\left(F_{\mathrm{o}}{ }^{2}-F_{\mathrm{c}}{ }^{2}\right)^{2} \\ \text { Data / restraints / parameters } & 8246 / 542 / 634 \\ \text { Goodness-of-fit on } \mathrm{F}^{2} & 1.026 \\ \Delta / \sigma_{\max } & 0.001 \\ \text { Final R indices } & 6053 \text { data; } I>2 \sigma(I) R_{1}=0.0599, w R_{2}=0.1097 \\ & \text { all data } \quad R_{1}=0.0881, w R_{2}=0.1205 \\ & \mathrm{w}=1 /\left[\sigma^{2}\left(F_{\mathrm{o}}{ }^{2}\right)+(0.0388 \mathrm{P})^{2}+3.4275 \mathrm{P}\right] \\ \text { Weighting scheme } & \text { where } \mathrm{P}=\left(F_{\mathrm{o}}{ }^{2}+2 F_{\mathrm{c}}{ }^{2}\right) / 3 \\ \text { Largest diff. peak and hole } & 0.625 \text { and }-0.638 \AA^{-3} \\ \text { R.M.S. deviation from mean } & 0.070 \AA^{-3}\end{array}$

Table S15. Bond lengths $(\AA)$ for $\mathrm{CoL}^{\mathrm{NO} 2}$.

$\begin{array}{llll}\text { C1-N1 } & 1.351(4) & \text { C1-C2 } & 1.387(4) \\ \text { C1-N8 } & 1.393(4) & \text { C2-C3 } & 1.372(5) \\ \text { C2-H2 } & 0.95 & \text { C3-C4 } & 1.382(5) \\ \text { C3-H3 } & 0.95 & \text { C4-C5 } & 1.381(4) \\ \text { C4-H4 } & 0.95 & \text { C5-N1 } & 1.349(4) \\ \text { C5-N2 } & 1.409(4) & \text { C6-N3 } & 1.351(4) \\ \text { C6-C7 } & 1.375(5) & \text { C6-N2 } & 1.415(4) \\ \text { C7-C8 } & 1.385(5) & \text { C7-H7 } & 0.95 \\ \text { C8-C9 } & 1.374(5) & \text { C8-H8 } & 0.95 \\ \text { C9-C10 } & 1.379(5) & \text { C9-H9 } & 0.95 \\ \text { C10-N3 } & 1.351(4) & \text { C10-N4 } & 1.405(4) \\ \text { C11-N5 } & 1.354(4) & \text { C11-N4 } & 1.392(4) \\ \text { C11-C12 } & 1.396(5) & \text { C12-C13 } & 1.365(5) \\ \text { C12-H12 } & 0.95 & \text { C13-C14 } & 1.373(5) \\ \text { C13-H13 } & 0.95 & \text { C14-C15 } & 1.385(4) \\ \text { C14-H14 } & 0.95 & \text { C15-N5 } & 1.350(4) \\ \text { C15-N6 } & 1.397(4) & \text { C16-N7 } & 1.357(4) \\ \text { C16-C17 } & 1.383(5) & \text { C16-N6 } & 1.401(4) \\ \text { C17-C18 } & 1.379(4) & \text { C17-H17 } & 0.95 \\ \text { C18-C19 } & 1.371(5) & \text { C18-H18 } & 0.95 \\ \text { C19-C20 } & 1.385(4) & \text { C19-H19 } & 0.95 \\ \text { C20-N7 } & 1.353(4) & \text { C20-N8 } & 1.393(4) \\ \text { C21-C22 } & 1.391(5) & \text { C21-C26 } & 1.391(5) \\ \text { C21-N2 } & 1.428(4) & \text { C22-C23 } & 1.381(5) \\ \text { C22-H22 } & 0.95 & \text { C23-C24 } & 1.379(6) \\ \text { C23-H23 } & 0.95 & \text { C24-C25 } & 1.381(5) \\ \text { C24-H24 } & 0.95 & \text { C25-C26 } & 1.385(5) \\ \text { C25-H25 } & 0.95 & \text { C26-N10 } & 1.474(4) \\ \text { C27-N4 } & 1.469(4) & \text { C27-H27A } & 0.98 \\ \text { C27-H27B } & 0.98 & \text { C27-H27C } & 0.98\end{array}$




$\begin{array}{llll}\text { C28-N6 } & 1.465(4) & \text { C28-H28A } & 0.98 \\ \text { C28-H28B } & 0.98 & \text { C28-H28C } & 0.98 \\ \text { C29-N8 } & 1.465(4) & \text { C29-H29A } & 0.98 \\ \text { C29-H29B } & 0.98 & \text { C29-H29C } & 0.98 \\ \text { C30-C31 } & 1.452(5) & \text { C30-H30A } & 0.98 \\ \text { C30-H30B } & 0.98 & \text { C30-H30C } & 0.98 \\ \text { C31-N9 } & 1.139(4) & \text { Co1-N7 } & 1.919(3) \\ \text { Co1-N5 } & 1.925(2) & \text { Co1-N1 } & 1.928(2) \\ \text { Co1-N3 } & 1.929(3) & \text { Co1-N9 } & 2.161(3) \\ \text { N10-O1' } & 1.142(8) & \text { N10-O2 } & 1.172(4) \\ \text { N10-O1 } & 1.268(5) & \text { N10-O2' } & 1.344(7) \\ \text { C11-O4 } & 1.411(10) & \text { Cl1-O6 } & 1.416(9) \\ \text { C11-O5 } & 1.424(9) & \text { C11-O3 } & 1.433(9) \\ \text { C11'-O6' } & 1.398(10) & \text { C11'-O5' } & 1.403(11) \\ \text { C11'-O3' } & 1.413(10) & \text { C11'-O4' } & 1.429(11) \\ \text { C12-O10 } & 1.409(3) & \text { Cl2-O8 } & 1.428(3) \\ \text { C12-O7 } & 1.431(2) & \text { C12-O9 } & 1.453(3) \\ \text { C32-C33 } & 1.476(9) & \text { C32-H32A } & 0.98 \\ \text { C32-H32B } & 0.98 & \text { C32-H32C } & 0.98 \\ \text { C33-N11 } & 1.126(7) & \text { C32'-C33' } & 1.478(15) \\ \text { C32'-H32D } & 0.98 & \text { C32'-H32E } & 0.98 \\ \text { C32'-H32F } & 0.98 & \text { C33'-N11' } & 1.131(14) \\ \text { C34-C35 } & 1.542(10) & \text { C34-H34A } & 0.98 \\ \text { C34-H34B } & 0.98 & \text { C34-H34C } & 0.98 \\ \text { C35-N12 } & 1.134(7) & \text { C34'-C35' } & 1.57(2) \\ \text { C34'-H34D } & 0.98 & \text { C34'-H34E } & 0.98 \\ \text { C34'-H34F } & 0.98 & \text { C35'-N12' } & 1.109(18) \\ & & & \end{array}$

Table S16. Bond angles $\left({ }^{\circ}\right)$ for $\mathbf{C o L}^{\mathrm{NO} 2}$.

$\begin{array}{llll}\text { N1-C1-C2 } & 121.9(3) & \text { N1-C1-N8 } & 116.8(3) \\ \text { C2-C1-N8 } & 121.3(3) & \text { C3-C2-C1 } & 118.6(3) \\ \text { C3-C2-H2 } & 120.7 & \text { C1-C2-H2 } & 120.7 \\ \text { C2-C3-C4 } & 120.2(3) & \text { C2-C3-H3 } & 119.9 \\ \text { C4-C3-H3 } & 119.9 & \text { C5-C4-C3 } & 118.5(3) \\ \text { C5-C4-H4 } & 120.8 & \text { C3-C4-H4 } & 120.8 \\ \text { N1-C5-C4 } & 122.1(3) & \text { N1-C5-N2 } & 116.5(3) \\ \text { C4-C5-N2 } & 121.4(3) & \text { N3-C6-C7 } & 122.8(3) \\ \text { N3-C6-N2 } & 116.1(3) & \text { C7-C6-N2 } & 121.0(3) \\ \text { C6-C7-C8 } & 117.9(3) & \text { C6-C7-H7 } & 121.1 \\ \text { C8-C7-H7 } & 121.1 & \text { C9-C8-C7 } & 120.0(3) \\ \text { C9-C8-H8 } & 120.0 & \text { C7-C8-H8 } & 120.0 \\ \text { C8-C9-C10 } & 119.1(3) & \text { C8-C9-H9 } & 120.4 \\ \text { C10-C9-H9 } & 120.4 & \text { N3-C10-C9 } & 121.6(3)\end{array}$




\begin{tabular}{|c|c|c|c|}
\hline N3-C10-N4 & $117.2(3)$ & C9-C10-N4 & $121.2(3)$ \\
\hline N5-C11-N4 & $117.5(3)$ & N5-C11-C12 & $121.2(3)$ \\
\hline N4-C11-C12 & $121.2(3)$ & C13-C12-C11 & $118.8(3)$ \\
\hline C13-C12-H12 & 120.6 & C11-C12-H12 & 120.6 \\
\hline C12-C13-C14 & $120.4(3)$ & $\mathrm{C} 12-\mathrm{C} 13-\mathrm{H} 13$ & 119.8 \\
\hline C14-C13-H13 & 119.8 & C13-C14-C15 & $118.6(4)$ \\
\hline C13-C14-H14 & 120.7 & C15-C14-H14 & 120.7 \\
\hline N5-C15-C14 & $122.0(3)$ & N5-C15-N6 & $117.3(3)$ \\
\hline C14-C15-N6 & $120.7(3)$ & N7-C16-C17 & $122.2(3)$ \\
\hline N7-C16-N6 & $116.6(3)$ & C17-C16-N6 & 121.2(3) \\
\hline C18-C17-C16 & $118.4(3)$ & C18-C17-H17 & 120.8 \\
\hline C16-C17-H17 & 120.8 & C19-C18-C17 & $120.4(3)$ \\
\hline C19-C18-H18 & 119.8 & C17-C18-H18 & 119.8 \\
\hline C18-C19-C20 & $118.4(3)$ & C18-C19-H19 & 120.8 \\
\hline C20-C19-H19 & 120.8 & N7-C20-C19 & $122.5(3)$ \\
\hline N7-C20-N8 & $116.7(3)$ & $\mathrm{C} 19-\mathrm{C} 20-\mathrm{N} 8$ & $120.8(3)$ \\
\hline $\mathrm{C} 22-\mathrm{C} 21-\mathrm{C} 26$ & $117.9(3)$ & $\mathrm{C} 22-\mathrm{C} 21-\mathrm{N} 2$ & $121.6(3)$ \\
\hline C26-C21-N2 & $120.5(3)$ & $\mathrm{C} 23-\mathrm{C} 22-\mathrm{C} 21$ & $120.5(4)$ \\
\hline C23-C22-H22 & 119.7 & $\mathrm{C} 21-\mathrm{C} 22-\mathrm{H} 22$ & 119.7 \\
\hline C24-C23-C22 & $120.7(4)$ & C24-C23-H23 & 119.7 \\
\hline $\mathrm{C} 22-\mathrm{C} 23-\mathrm{H} 23$ & 119.7 & $\mathrm{C} 23-\mathrm{C} 24-\mathrm{C} 25$ & $119.9(3)$ \\
\hline C23-C24-H24 & 120.1 & $\mathrm{C} 25-\mathrm{C} 24-\mathrm{H} 24$ & 120.1 \\
\hline $\mathrm{C} 24-\mathrm{C} 25-\mathrm{C} 26$ & $119.2(4)$ & $\mathrm{C} 24-\mathrm{C} 25-\mathrm{H} 25$ & 120.4 \\
\hline $\mathrm{C} 26-\mathrm{C} 25-\mathrm{H} 25$ & 120.4 & $\mathrm{C} 25-\mathrm{C} 26-\mathrm{C} 21$ & $121.8(3)$ \\
\hline C25-C26-N10 & $116.5(3)$ & C21-C26-N10 & $121.7(3)$ \\
\hline N4-C27-H27A & 109.5 & N4-C27-H27B & 109.5 \\
\hline $\mathrm{H} 27 \mathrm{~A}-\mathrm{C} 27-\mathrm{H} 27 \mathrm{~B}$ & 109.5 & N4-C27-H27C & 109.5 \\
\hline $\mathrm{H} 27 \mathrm{~A}-\mathrm{C} 27-\mathrm{H} 27 \mathrm{C}$ & 109.5 & $\mathrm{H} 27 \mathrm{~B}-\mathrm{C} 27-\mathrm{H} 27 \mathrm{C}$ & 109.5 \\
\hline N6-C28-H28A & 109.5 & N6-C28-H28B & 109.5 \\
\hline $\mathrm{H} 28 \mathrm{~A}-\mathrm{C} 28-\mathrm{H} 28 \mathrm{~B}$ & 109.5 & N6-C28-H28C & 109.5 \\
\hline $\mathrm{H} 28 \mathrm{~A}-\mathrm{C} 28-\mathrm{H} 28 \mathrm{C}$ & 109.5 & $\mathrm{H} 28 \mathrm{~B}-\mathrm{C} 28-\mathrm{H} 28 \mathrm{C}$ & 109.5 \\
\hline N8-C29-H29A & 109.5 & N8-C29-H29B & 109.5 \\
\hline H29A-C29-H29B & 109.5 & N8-C29-H29C & 109.5 \\
\hline H29A-C29-H29C & 109.5 & $\mathrm{H} 29 \mathrm{~B}-\mathrm{C} 29-\mathrm{H} 29 \mathrm{C}$ & 109.5 \\
\hline C31-C30-H30A & 109.5 & C31-C30-H30B & 109.5 \\
\hline $\mathrm{H} 30 \mathrm{~A}-\mathrm{C} 30-\mathrm{H} 30 \mathrm{~B}$ & 109.5 & C31-C30-H30C & 109.5 \\
\hline $\mathrm{H} 30 \mathrm{~A}-\mathrm{C} 30-\mathrm{H} 30 \mathrm{C}$ & 109.5 & H30B-C $30-\mathrm{H} 30 \mathrm{C}$ & 109.5 \\
\hline N9-C31-C30 & $178.9(4)$ & N7-Co1-N5 & $90.56(11)$ \\
\hline N7-Co1-N1 & $88.26(10)$ & N5-Co1-N1 & $174.98(11)$ \\
\hline N7-Co1-N3 & $173.49(11)$ & N5-Co1-N3 & $88.95(11)$ \\
\hline N1-Co1-N3 & $91.66(11)$ & N7-Co1-N9 & $96.16(10)$ \\
\hline N5-Co1-N9 & $95.36(10)$ & N1-Co1-N9 & $89.62(10)$ \\
\hline N3-Co1-N9 & $90.34(10)$ & C5-N1-C1 & $118.6(3)$ \\
\hline C5-N1-Co1 & $120.89(19)$ & C1-N1-Co1 & $120.4(2)$ \\
\hline
\end{tabular}




\begin{tabular}{|c|c|c|c|}
\hline C5-N2-C6 & $120.3(3)$ & $\mathrm{C} 5-\mathrm{N} 2-\mathrm{C} 21$ & $119.5(2)$ \\
\hline C6-N2-C21 & $119.5(2)$ & C10-N3-C6 & $118.4(3)$ \\
\hline C10-N3-Co1 & $120.6(2)$ & C6-N3-Co1 & $121.0(2)$ \\
\hline C11-N4-C10 & $119.3(3)$ & C11-N4-C27 & $117.6(3)$ \\
\hline C10-N4-C27 & $116.8(3)$ & C15-N5-C11 & $118.7(3)$ \\
\hline C15-N5-Co1 & $120.8(2)$ & C11-N5-Co1 & $120.4(2)$ \\
\hline C15-N6-C16 & $119.4(3)$ & C15-N6-C28 & $117.6(3)$ \\
\hline C16-N6-C28 & $117.0(3)$ & C20-N7-C16 & $117.9(3)$ \\
\hline C20-N7-Co1 & $120.8(2)$ & C16-N7-Co1 & $121.2(2)$ \\
\hline C1-N8-C20 & $118.8(2)$ & C1-N8-C29 & $118.5(3)$ \\
\hline C20-N8-C29 & 117.1(3) & C31-N9-Co1 & $162.2(3)$ \\
\hline O2-N10-O1 & $124.3(4)$ & O1'-N10-O2' & $120.1(5)$ \\
\hline $\mathrm{O} 11^{\prime}-\mathrm{N} 10-\mathrm{C} 26$ & $124.7(5)$ & $\mathrm{O} 2-\mathrm{N} 10-\mathrm{C} 26$ & $120.7(3)$ \\
\hline O1-N10-C26 & $114.3(3)$ & O2'-N10-C26 & $114.2(4)$ \\
\hline O4-C11-O6 & $108.9(10)$ & O4-C11-O5 & $112.1(10)$ \\
\hline O6-C11-O5 & $107.8(10)$ & $\mathrm{O} 4-\mathrm{C} 11-\mathrm{O} 3$ & $112.9(11)$ \\
\hline O6-C11-O3 & $105.2(10)$ & $\mathrm{O} 5-\mathrm{C} 11-\mathrm{O} 3$ & $109.6(11)$ \\
\hline O6'-Cl1'-O5' & $110.2(11)$ & O6'-Cl1'-O3' & $113.4(13)$ \\
\hline O5'-Cl1'-O3' & $104.3(12)$ & O6'-Cl1'-O4' & $110.5(11)$ \\
\hline O5'-Cl1'-O4' & $109.7(12)$ & O3'-Cl1'-O4' & $108.7(12)$ \\
\hline $\mathrm{O} 10-\mathrm{C} 12-\mathrm{O} 8$ & $111.4(2)$ & $\mathrm{O} 10-\mathrm{Cl} 2-\mathrm{O} 7$ & $108.9(2)$ \\
\hline $\mathrm{O} 8-\mathrm{Cl} 2-\mathrm{O} 7$ & $109.16(16)$ & O10-Cl2-O9 & $110.8(2)$ \\
\hline O8-Cl2-O9 & $109.21(18)$ & O7-C12-O9 & $107.28(18)$ \\
\hline C33-C32-H32A & 109.5 & C33-C32-H32B & 109.5 \\
\hline $\mathrm{H} 32 \mathrm{~A}-\mathrm{C} 32-\mathrm{H} 32 \mathrm{~B}$ & 109.5 & C33-C32-H32C & 109.5 \\
\hline $\mathrm{H} 32 \mathrm{~A}-\mathrm{C} 32-\mathrm{H} 32 \mathrm{C}$ & 109.5 & $\mathrm{H} 32 \mathrm{~B}-\mathrm{C} 32-\mathrm{H} 32 \mathrm{C}$ & 109.5 \\
\hline N11-C33-C32 & 178.3(9) & C33'-C32'-H32D & 109.5 \\
\hline C33'-C32'-H32E & 109.5 & H32D-C32'-H32E & 109.5 \\
\hline C33'-C32'-H32F & 109.5 & H32D-C32'-H32F & 109.5 \\
\hline H32E-C32'-H32F & 109.5 & N11'-C33'-C32' & 172.(2) \\
\hline C35-C34-H34A & 109.5 & C35-C34-H34B & 109.5 \\
\hline H34A-C34-H34B & 109.5 & C35-C34-H34C & 109.5 \\
\hline H34A-C34-H34C & 109.5 & H34B-C34-H34C & 109.5 \\
\hline N12-C35-C34 & $165.3(6)$ & C35'-C34'-H34D & 109.5 \\
\hline C35'-C34'-H34E & 109.5 & H34D-C34'-H34E & 109.5 \\
\hline C35'-C34'-H34F & 109.5 & H34D-C34'-H34F & 109.5 \\
\hline H34E-C34'-H34F & 109.5 & N12'-C35'-C34' & 179.(6) \\
\hline
\end{tabular}

\section{REFERENCES:}

1. Zhang, E.-X.; Wang, D.-X.; Huang, Z.-T.; Wang, M.-X., Synthesis of (NH)m(NMe)4-m-Bridged Calix[4]pyridines and the Effect of NH Bridge on Structure and Properties. The Journal of Organic Chemistry 2009, 74 (22), 8595-8603.

2. Fang, Y.-X.; Ao, Y.-F.; Wang, D.-X.; Zhao, L.; Wang, M.-X., Synthesis, Structure and Transition Metal Ion Complexation Property of Lariat Azacalix[4]pyridines. Tetrahedron 2015, 71 (14), 2105-2112. 
3. Saint+ V8.27B, Bruker AXS, Madison, WI, 2011.

4. $\quad$ SADABS V2012-1, Bruker AXS, Madison, WI, 2012.

5. Sheldrick, G. M.; Acta Cryst.2015, A71, 3-8; Acta Cryst.2008, A64, 112-122; Acta Cryst.2015, C71, 3-8; Hübschle, C. B.; Sheldrick, G. M.; Dittrich,B., J. Appl. Cryst.2011, 44, 1281-1284; SHELXL 2014/7, G. M. Sheldrick, 2014; SHELXTL V2014/1,Bruker AXS, Madison, WI, 2014.

6. McCarthy, B. D.; Martin, D. J.; Rountree, E. S.; Ullman, A. C.; Dempsey, J. L. Electrochemical Reduction of Brønsted Acids by Glassy Carbon in Acetonitrile-Implications for Electrocatalytic Hydrogen Evolution. Inorg. Chem. 2014, 53, 8350-8361.

7. Lam, Y. C.; Nielsen, R. J.; Gray, H. B.; Goddard, W. A. A Mn Bipyrimidine Catalyst Predicted to Reduce $\mathrm{CO}_{2}$ at Lower Overpotential. ACS Catal. 2015, 5, 2521-2528.

8. Kütt, A.; Movchun, V.; Rodima, T.; Dansauer, T.; Rusanov, E. B.; Leito, I.; Kaljurand, I.; Koppel, J.; Pihl, V.; Koppel, I.; et al. Pentakis(Trifluoromethyl)Phenyl, a Sterically Crowded and Electron-Withdrawing Group: Synthesis and Acidity of Pentakis(Trifluoromethyl)Benzene, -Toluene, -Phenol, and -Aniline. J. Org. Chem. 2008, 73, 2607-2620.

9. Matsubara, Y.; Grills, D. C.; Kuwahara, Y. Thermodynamic Aspects of Electrocatalytic $\mathrm{CO}_{2}$ Reduction in Acetonitrile and with an Ionic Liquid as Solvent or Electrolyte. ACS Catal. 2015, 5, 6440-6452. 